\title{
Vegetable oil-derived epoxy monomers and polymer blends: A comparative study with review
}

\author{
R. Wang, T. P. Schuman* \\ Department of Chemistry, Missouri University of Science and Technology, MO 65409 Rolla, USA
}

Received 13 September 2012; accepted in revised form 18 November 2012

\begin{abstract}
Glycidyl esters of epoxidized fatty acids derived from soybean oil (EGS) and linseed oil (EGL) have been synthesized to have higher oxirane content, more reactivity and lower viscosity than epoxidized soybean oil (ESO) or epoxidized linseed oil (ELO). The EGS and ESO, for comparison, were used neat and in blends with diglycidyl ether of bisphenol A (DGEBA). Thermosetting resins were fabricated with the epoxy monomers and either $\mathrm{BF}_{3}$ catalyst or anhydride. The curing behaviors, glass transition temperatures, crosslink densities and mechanical properties were tested. The results indicated that polymer glass transition temperatures were mostly a function of oxirane content with additional influence of glycidyl versus internal oxirane reactivity, pendant chain content, and chemical structure and presence of saturated components. EGS provided better compatibility with DGEBA, improved intermolecular crosslinking and glass transition temperature, and yielded mechanically stronger polymerized materials than materials obtained using ESO. Other benefits of the EGS resin blend systems were significantly reduced viscosities compared to either DGEBA or ESO-blended DGEBA counterparts. Therefore, EGS that is derived from renewable sources has improved potential for fabrication of structural and structurally complex epoxy composites, e.g., by vacuum-assisted resin transfer molding.
\end{abstract}

Keywords: thermosetting resins, mechanical properties, thermal properties, biopolymers, epoxy

\section{Introduction}

Since petroleum resources are ultimately limited, polymers based on vegetable oils are of great interest because they are renewable and could significantly contribute to a more sustainable development $[1,2]$. Vegetable oils such as linseed and tung oil are drying oils, which can self-crosslink under atmospheric oxygen, have long been used in the coating industry [3]. Semi-drying oils like soybean oil are of plentiful supply and therefore of relatively low cost, have also attracted great interest for the preparation of polymers or resins [4]. In recent years, with the rising cost of fossil raw materials and environmental issues, polymers derived from soybean oil have demonstrated strong cost/performance competitiveness in many market applications [5]. However, the ability to obtain structures of sufficient mechanical or thermal properties has remained a challenge.

For instance, direct radical or cationic polymerization of vegetable oils is structurally difficult due to the non-conjugated, internal double bonds and only viscous liquid polymers with low molecular weight are formed [6]. On the other hand, polymers ranging from soft rubbers to hard plastics have been prepared by the cationic copolymerization of soybean oil blended with divinylbenzene (DVB). Styrene was added to reduce the heterogeneity of the crosslinked structures caused by incompatibility between monomers and the modulus of polymer was dependent on the styrene and, particularly, the DVB content [7].

Epoxidation of vegetable oils using peracids, such as Epoxidized soybean oil (ESO) and epoxidized

\footnotetext{
${ }^{*}$ Corresponding author, e-mail: tschuman@mst.edu

(C) BME-PT
} 
linseed oil (ELO), is one of the most important and useful exploitations of double bonds since epoxides are reactive intermediates that are also readily converted to other functional groups through ring-opening reactions. Sheet molding compound (SMC) resins have been made from epoxidized soybean oil modified with unsaturated functional groups like acrylic acid or maleic anhydride where styrene was employed as a comonomer to reduce the viscosity of the resin $[8,9]$. The SMC was obtained via common radical polymerization fashion. Allyl alcohol ring-opened ESO has been copolymerized with maleic anhydride (MA) to prepare thermosets by esterification and free radical polymerization. The resulting glass transition temperatures $\left(T_{\mathrm{g}}\right)$ and mechanical strengths were dependent on the loading of MA [10]. Soy based polyols derived from ESO have also been widely used to produce polyurethanes that are comparable in many aspects with polyurethanes obtained from petrochemical polyols [11].

ESO can be crosslinked into thermosetting polymers by various curing agents [12]. However, due to lower oxirane content and sluggish reactivity of the internal oxirane, the cured ESO polymers normally have low crosslinking density. Poorer thermal and mechanical properties result from both partially unreacted ESO and saturated fatty acid (FA) chains that reduce reactivity and self-plasticize. Most ESO industrial uses are thus limited to nonstructural, additive applications such as plasticizers or stabilizers for poly (vinyl chloride) [13], oil-base coatings [14] with low strength requirements [15]. Though the mechanical strength of cured ESO can be improved with the addition of nano-reinforcements [16], or fiber reinforcement [17], an inherently low $T_{\mathrm{g}}$ inevitably limits practical applications because $T_{\mathrm{g}}$ for a polymer must be appropriately higher than the temperature of its intended work environment to serve as a useful plastic [18]. When used as a matrix material in composites, the resin state is desired to be rigid/glassy, i.e., below its $T_{\mathrm{g}}$, to effectively transfer energy to fibers [19].

ESO has a moderate viscosity so ESO or their derivatives can be used as reactive diluents for the partial replacement of diglycidyl ether of bisphenol A (DGEBA) resins, which are relatively high viscosity liquids or solids, to decrease the overall cost and improve the processability [20-22]. Generally, the mechanical strengths and thermal properties of
ESO blended resins are not comparable to those of pure DGEBA epoxy resins, while their toughness can be better due to the introduction of a two phase structure [23-26]. However, due to the inhomogeneous structure, ESO is not as efficient in reducing the viscosity of epoxy resin compared to most petroleum based reactive diluents. A further increase in the ESO concentration inevitably leads to a significant decrease in performance of cured resin. There are few reports of high ESO replacement [20] because low oxirane content and the unreactive saturated component of ESO both lead to a low crosslink density upon cure and a poor miscibility exists between ESO and the DGEBA. There is an especially large difference in the reactivity of the internal oxirane in ESO and terminal oxirane in DGEBA and, as we will show, heterogeneous structures form during the curing reaction that leads to a phase separated materials of poorer mechanical /thermal performance.

More reactive terminal epoxy derived from chlorinated ESO has been reported and used as a matrix with DGEBA for glass fiber composites [27]. The dehydrochlorination under alkaline conditions will hydrolyze ester groups of triglycerides, even at room temperature. A triglyceride with terminal epoxy has been synthesized from 10-undecenoic acid and successfully used in epoxy-amine curing [28, 29], whereas 10-undecylenic acid, a derivative of castor oil, has only one terminal double bond so the epoxidized triglyceride ester of 10-undecylenic acid has a lower oxirane content compared to ESO. Largescale production also seems impractical [30]. Only those oils of poly-unsaturated FA content, especially soybean or linseed oils, that can produce dense oxirane functional resins are capable to produce satisfactory properties [12, 31-33]. Epoxidized vegetable oils (EVO) of low oxirane values either are not reactive or impart waxy, non-curing properties to the resin system.

Vegetable oils contain several actives sites amenable to chemical modification. The double bonds in FA chains and the ester groups in the glyceryl part are the most important. These active sites can be used to introduce reactive groups. ESO and aforementioned derivatives are most focused on the modification of FA chain. On the ester side, epoxidized methyl oleate [34], epoxidized methyl soyate, epoxidized allyl soyate [35], epoxidized sunflower oil biodiesel [36] and linseed oil epoxidized methyl 
esters [37] have been shown to have lower viscosity and more reactive compared to their ESO or ELO counterparts.

A caveat in the addition of functional groups, such as unreactive methyl or reactive allyl through transesterification, is a potential decrease of crosslinking density and final properties of cured resins upon breaking the oligomeric triglyceride structure. FA chain ends at the ester become pendant after transesterification and are dependent on crosslinking to build molecular weight. Esters of saturated FAs may only behave as plasticizers [38]. Novel epoxy compounds such as epoxidized sucrose esters of fatty acids have been synthesized and crosslinked to prepare polyester thermosets [30, 39]. High modulus polymer was achieved due to the well-defined compact macromolecular structures and high oxirane functionality. Some applications may be hampered by their high viscosities.

Modified ELO synthesized through Diels-Alder reaction of dicyclopentadiene [40] or 1,3-butadiene [41] with linseed oil have been reported. The modified ELO resins still possessed internal oxirane and thus are more suitable for cationic cure. End users still seek economical bio-based epoxies that are competitive with petroleum-based epoxies [30].

Vegetable oils generally have variable levels of saturated FA content, for example, soybean oil normally has about $15 \%$ saturated FAs ( $4.0 \%$ stearic and $\sim 11 \%$ palmitic) that varies with plant variety, growing regions, and weather. Saturated FAs have no functional groups within the FA chain that then act as dangling chains, low in reactivity, to plasticize the final polymer. The saturated chains are detrimental to the final properties of polymers [42, 43]. To improve reactivity and to increase hydroxyl number of soy based polyols, regionally selective enzymatic hydrolysis has been attempted to liberate saturated FAs, which were then removed by alkaline washing [44]. Total removal of saturated components is difficult and is also accompanied by partial hydrolysis of unsaturated FA esters. Conversion of oil triglyceride into free fatty acid (FFA) or FA derivatives allows separation of unsaturated and sat- urated components on the basis of solubility through crystallization. The degree of unsaturation of FFA considerably changes the melting point and thus separation of mixtures of saturated and unsaturated FFAs can be readily achieved by proper choice of organic solvents and temperatures [45].

In this research, EGS were synthesized and examined. The goals were to remove and assess the role of the plasticizing effect of saturated components, to increase and assess the role of the oxirane content, and to minimize viscosity toward developing either a capable reactive diluent for commercial epoxy or a new commercial epoxy resin of its own right. The study gave us the opportunity to study how saturated component, oxirane type and oxirane content translate into curing, thermal and mechanical properties. We hypothesized that EGS as the ester of a terminal oxirane group (glycidyl), which is then readily accessible to nucleophilic attack, should further enable reactivity compared with the currently standard, commercial ESO and consequently reduce the molecular size and facilitate removal of the saturated FA components. We thus proposed to increase oxirane content. The goals and resin design were intended to provide a dense, intermolecular crosslinking structure and yield a more consistent thermosetting resin material with improved properties.

\section{Experimental \\ 2.1. Materials}

Refined, food grade soybean oil (Great Value ${ }^{\mathrm{TM}}$, WalMart, Bentonville, AR, USA) was purchased. Linseed oil was purchased from Archer Daniels Midland Company (Red Wing, MN, USA). The major FA distributions [46] reported for soybean oil and linseed oil are listed in Table 1. ESO was obtained from Union Carbide Corporation (Danbury, CT, USA). ELO was obtained from Arkema, Inc. (Philadelphia, PA, USA). Acetone, allyl alcohol, epichlorohydrin $(\mathrm{EPCH})$, methylene chloride, methanol, meta-chloroperoxybenzoic acid (MCPBA), potassium hydroxide, sodium carbonate, sodium bicarbonate, sodium hydroxide, sodium sulfite, and anhy-

Table 1. Fatty acids profile in vegetable oils

\begin{tabular}{|l|c|c|c|c|c|}
\hline \multicolumn{1}{|c|}{ Fatty Acid (x:y) } & Palmitic (14:0) & Stearic (18:0) & Oleic (18:1) & Linoleic (18:2) & Linolenic (18:3) \\
\hline Soybean oil [\%] & 11 & 4 & 23 & 53 & 8 \\
\hline Linseed oil [\%] & 5 & 4 & 19 & 15 & 57 \\
\hline
\end{tabular}

Legend $(x: y): x$, number of carbon atoms; $y$, number of double bonds. Fatty acid contents do not add to $100 \%$ due to presence of minor fatty acid content. 
drous sodium sulfate were purchased from Fisher Scientific (St. Louis, MO, USA). Cetyltrimethylammonium bromide (CTAB), boron trifluoride monoethyl amine complex ( $\mathrm{BF}_{3}$-MEA), 2-ethyl-4-methylimidazole (EMI), hydrochloric acid and 4-methyl1,2-cyclohexanedicarboxylic anhydride (MHHPA) were purchased from Aldrich (St. Louis, MO, USA). Commercial DGEBA was supplied by Momentive (Deer Park, TX, USA) with trade name EPONTM Resin 828. Mold release agent Chemlease ${ }^{\circledR}$ 41-90 EZ was purchased from Chem-Trend, Inc. (Howell, MI, USA)

\subsection{Chemical characterization}

Infrared spectra (IR) were measured with a Nicolet Nexus 470 E.S.P. spectrophotometer (Waltham, MA, USA). ${ }^{1} \mathrm{H}$ NMR spectra were obtained on a Varian INOVA $400 \mathrm{MHz}$ spectrometer (Palo Alto, CA, USA) using $d_{6}$-DMSO as solvent. Iodine value was assessed using ASTM Method D5554-95. Oxirane oxygen value was measured using AOCS Method Cd 9-57.

\subsection{Soap and free fatty acid preparation}

Free fatty acids were made via acid neutralization of soap. Vegetable oil and water mixture $(800 \mathrm{~g}$, 50:50) was reacted with sodium hydroxide solution (200 g, $30 \mathrm{wt} \%$ ) at $60^{\circ} \mathrm{C}$ for $4 \mathrm{hr}$ to generate soap and then acidified with sulfuric acid $(270 \mathrm{~g}$, $30 \mathrm{wt} \%$ ) to $\mathrm{pH}<2$. The lower aqueous layer including sodium sulfate and glycerin was separated, washing the top FFA layer using $60^{\circ} \mathrm{C}$ water. Finally the liquid organic FFA layer (339 g) was dried using anhydrous sodium sulfate. The iodine value of the soybean FFA was 133.

Freshly prepared FFA was dissolved in acetone based on the weight ratio of 1:6 and then purged with nitrogen gas, cooled to $-20^{\circ} \mathrm{C}$ for overnight. The formed crystals were removed by vacuum filtration. The procedure could be repeated several times until no further crystals were generated. For these studies, four times filtration were performed resulting in an iodine value for refined unsaturated soybean FFA of 150.

To a FFA/acetone solution ( $500 \mathrm{~g}$ ) of weight ratio of $1: 10,110 \%$ of stoichiometric sodium hydroxide solution $(18 \mathrm{~mL}, 10 \mathrm{M})$ based on amount of FFA (average molecular weight treated as $278 \mathrm{~g} / \mathrm{mol}$ ) was added dropwise. The neutralization reaction was continued for $4 \mathrm{hr}$ under nitrogen gas to pre- vent air oxidation of the soap. The soap powder was readily filtered by vacuum filtration and then dried at $110^{\circ} \mathrm{C}$ for $1.5 \mathrm{hr}$.

\subsection{Glycidyl esters of epoxidized fatty acids preparation}

Dry soap (302 g) and EPCH (925 g) were heated to reflux. Phase transfer catalyst CTAB (7.3 g) at 2 equivalent- $\%$ per equivalent soap was then added. Reflux was continued for $30 \mathrm{~min}$, cooled and centrifuged, the clear solution was decanted to a flask. Excess EPCH was removed using in vacuo rotary evaporation. Oxirane oxygen value of prepared glycidyl ester was $4.4 \%$ (theoretical value of $4.7 \%$ for glycidyl oleate).

Glycidyl ester (341 g) and sodium carbonate (64 g) were mixed with methylene chloride $(200 \mathrm{ml})$. MCPBA (367 g, $75 \mathrm{wt} \%$ ) dissolved in methylene chloride at $0.1 \mathrm{~g} / \mathrm{ml}$ concentration was added dropwise at a reaction temperature below $15^{\circ} \mathrm{C}$ and then reacted for $4 \mathrm{hr}$ to complete epoxidation. The reaction mixture was washed with $10 \mathrm{wt} \%$ sodium sulfite $(200 \mathrm{~g})$ and then by $10 \mathrm{wt} \%$ aqueous sodium bicarbonate $(150 \mathrm{~g})$. Methylene chloride was removed by in vacuo rotary evaporation and the product EGS (345 g) was dried over anhydrous sodium sulfate. Linseed oil based glycidyl esters of epoxidized fatty acids (EGL) were also prepared based on the above mentioned procedure. For EGSS/EGL-S, saturated FFAs were not removed and remain in EGS/EGL. For EGS-P/EGL-P, FAs were partially epoxidized. Soybean oil based epoxidized methyl ester (EMS) and epoxidized allyl ester (EAS) were formed by standard alkaline transesterification with the corresponding alcohols and then epoxidized by MCPBA, e.g., potassium hydroxide $(2.2 \mathrm{~g})$ was first crushed and dissolved in allyl alcohol $(260 \mathrm{~g})$, then poured into soybean oil $(220 \mathrm{~g})$. Mixtures were heated under reflux condition for $4 \mathrm{hrs}$. Workup included potassium hydroxide discharged by the addition of concentrated hydrochloric acid (3.9 g, $37 \mathrm{wt} \%)$, removal of the excess allyl alcohol using in vacuo rotary evaporation, washing of the allyl esters of soybean oil four times with distilled water to remove glycerin, salt, and any residual allyl alcohol, and then drying with anhydrous sodium sulfate and filtration to remove the sodium sulfate. The method for epoxidation of allyl esters of soybean oil by MCPBA is the above-mentioned method for epoxidation of glycidyl esters. 


\subsection{Thermal characterization}

\subsubsection{Curing reactions}

The weight ratios of EGS/ESO to DGEBA resin blend chosen for the present work were 0:100 (pure DGEBA), 10:90, 30:70, 50:50, 70:30; 90:10 and 100:0 (pure EGS/ESO). A stoichiometric ratio $r=$ 1.0 of epoxy/anhydride was used for all samples and $1 \mathrm{wt} \%$ (based on epoxy part) of EMI were added to the blend. After mixing by a PowerGen 1000 homogenizer (Fisher Scientific, St. Louis, MO, USA) for $10 \mathrm{~min}$, the mixture was degassed under vacuum for $30 \mathrm{~min}$, then poured into a mold treated with mold release agent. Curing was performed at $145^{\circ} \mathrm{C}$ for $15 \mathrm{hr}$ for all blends except ESO-DGEBA (90:10) and pure ESO blend, which were inducted for $12 \mathrm{hr}$ at room temperature, remixed, poured into the mold and cured at $125^{\circ} \mathrm{C}$ for $15 \mathrm{hr}$. ESO required more stringent curing conditions due to the low reactivity and phase separation exhibited by ESO. Postcure for all samples was performed at $175^{\circ} \mathrm{C}$ for $1 \mathrm{hr}$.

Two to three milligrams of mixture was hermetically sealed in an aluminum pan and cured on a model Q2000 differential scanning calorimetry (DSC) machine (TA Instruments, New Castle, DE, USA) by scanning temperature at a heating rate of $10^{\circ} \mathrm{C} / \mathrm{min}$ from $40-250^{\circ} \mathrm{C}$ to study the cure behavior of each formulation.

Neat epoxy monomers were also cationically cured. A $3 \mathrm{wt} \%$ (based on epoxy) of $\mathrm{BF}_{3}$-MEA was mixed with monomer and cured at $150^{\circ} \mathrm{C}$ for $3 \mathrm{hr}$ followed by $185^{\circ} \mathrm{C}$ for $1 \mathrm{hr}$.

\subsubsection{Glass transition and degradation temperatures}

DSC was used to determine the glass transition of cured resin. Samples were first preheated at $20^{\circ} \mathrm{C} / \mathrm{min}$ to $180^{\circ} \mathrm{C}$ to remove any previous thermal history, and then quenched to $-40^{\circ} \mathrm{C}$. Heat flow was measured over a temperature range scanned from -40 to $180^{\circ} \mathrm{C}$ at a heating rate of $20^{\circ} \mathrm{C} / \mathrm{min}$. Universal Analysis 2000 software (TA Instruments, New Castle, DE, USA) was used to analyze the curve, inflection temperature $\left(T_{\mathrm{i}}\right)$ was reported as the glass transition temperature.

A model Q50 thermogravimetric analysis instrument (TGA, TA Instruments, New Castle, DE, USA) was used to determine the thermal degradation onset temperature of cured resin. Measurement was performed while scanning temperature from 30 to $750^{\circ} \mathrm{C}$ at a heating rate of $10^{\circ} \mathrm{C} / \mathrm{min}$ under an ambient air flow environment.

\subsection{Swelling test}

Approximately $0.2 \mathrm{~g}$ of the cured resins with a cubic shape $(8 \mathrm{~mm} \times 8 \mathrm{~mm} \times 3 \mathrm{~mm})$ were placed in toluene solvent until equilibrium was attained. To accelerate the swelling, samples were placed into a $45^{\circ} \mathrm{C}$ oven to attain a constant weight, then equilibrated at room temperature for one week. The swollen samples were removed from the solvents, quickly blotted dry with paper towel, and weighed. The equilibrium swelling ratio [47] of the cured resin was calculated based on Equation (1):

$Q=\frac{1}{\nu_{2}}=1+\frac{\left(\frac{m_{\mathrm{s}}}{m_{0}}-1\right) \cdot \rho_{\text {poly }}}{\rho_{\text {sol }}}$

where $Q$ is the equilibrium swelling ratio of the polymeric network, $v_{2}$ is the volume fraction of polymer at equilibrium swelling, $m_{0}$ is the mass of the polymeric network before swelling, $m_{\mathrm{s}}$ is the mass of the polymeric network at equilibrium swelling, and $\rho_{\text {sol }}$ and $\rho_{\text {poly }}$ are the densities of the solvent and polymeric network, respectively.

\subsection{Mechanical tests}

Tensile strengths and moduli were measured on a model 4469 Universal testing machine (Instron, Norwood, MA, USA) according to ASTM D638. All the tensile tests were performed at a crosshead speed of $10 \mathrm{~mm} / \mathrm{min}$. At least five specimens were tested for each different resin system. The flexural strengths and moduli were determined according to the ASTM method D790. The span was $50.8 \mathrm{~mm}$, the crosshead speed was set at $12.7 \mathrm{~mm} / \mathrm{min}$.

\subsection{Physical properties}

Viscosity was tested on a model LVDV-III+ Ultra Rheometer (Brookfield, Middleboro, MA, USA) at $25^{\circ} \mathrm{C}$. Liquid density was determined using the pycnometer method. Specific gravity of solid samples was measured by immersion in water using a model XP 204S balance (Mettler-Toledo, Columbus, OH, USA) with density measurement kits. 


\section{Results and discussion}

\subsection{Preparation of glycidyl esters of epoxidized fatty acids}

Figure 1 shows the synthetic route to EGS, generalized for oleic acid showing the process for a soybean triglyceride. Preparation of mixed FFAs from triglyceride is straightforward and well-developed. Methods of low temperature crystallization to remove the unsaturated FFAs are also well documented [48]. Most unsaturated FFAs are soluble in most organic solvents at temperature above $0^{\circ} \mathrm{C}$ while the saturated FFAs, which have higher melting points than unsaturated FFAs, are prone to form crystals/precipitates at low temperature in solvents like acetone or methanol. Although trace amounts of saturated FFAs remain unavoidably in the unsaturated FFAs after low temperature crystallization [49], further removal of saturated FA components was achieved after synthesis of glycidyl ester or EGS because glycidyl esters, or the epoxidized glycidyl esters, of unsaturated FAs are each liquid at room temperature and much lower in melting point than glycidyl esters of saturated FAs. The unsaturated esters are poorer solvents for saturated carbon chains, which are then more easily precipitated at room temperature. Although no FFA component analyses, like chromatography, were performed in this research, we believe the saturated components were minimized after three precipitations.

Acetone was used as a low boiling, recoverable solvent to prepare soap. A slight excess of $\mathrm{NaOH}$ and higher concentration was preferable when preparing soap from FFA because unsaturated FFAs were prone to dissolve in acetone rather than react with base. Unsaturated FFA soaps are more soluble in water [50]. Carefully dried and finely powdered soaps resulted in greater yields of glycidyl esters of FAs. [51]

A low solubility of soap in EPCH suggested that a phase transfer catalyst would be useful to accelerate the reaction. With CTAB catalyst, the consumption of soap was completed within half an hour under reflux condition. Glycidyl esters can also be prepared directly from FFA in EPCH medium but the yield and purity were lower than obtained by the soap process [50]. The epoxidation of glycidyl ester was carried out using MCPBA or in situ generated performic acid. The former was more efficient. Due to the low solubility of MCPBA in methylene chlo-

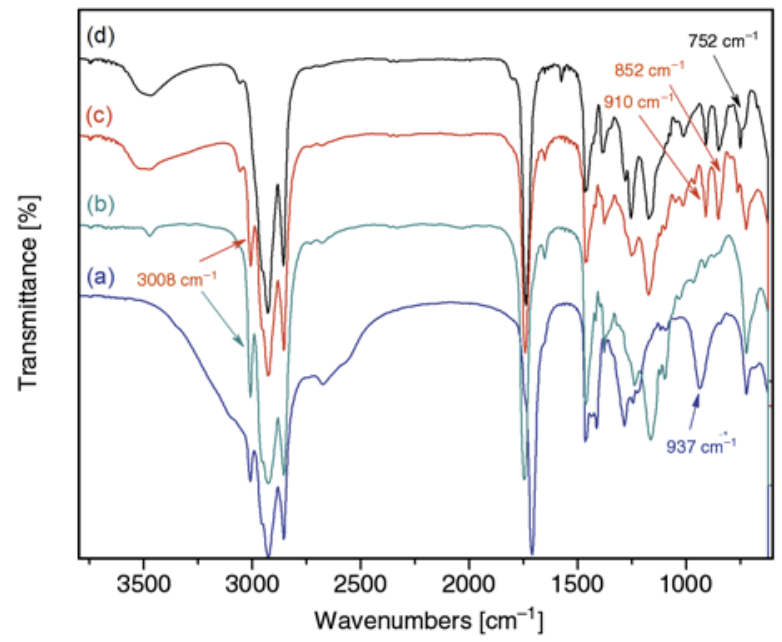

Figure 2. IR spectra of (a): mixed-FFA (b): soybean oil (c): glycidyl esters (d): EGS

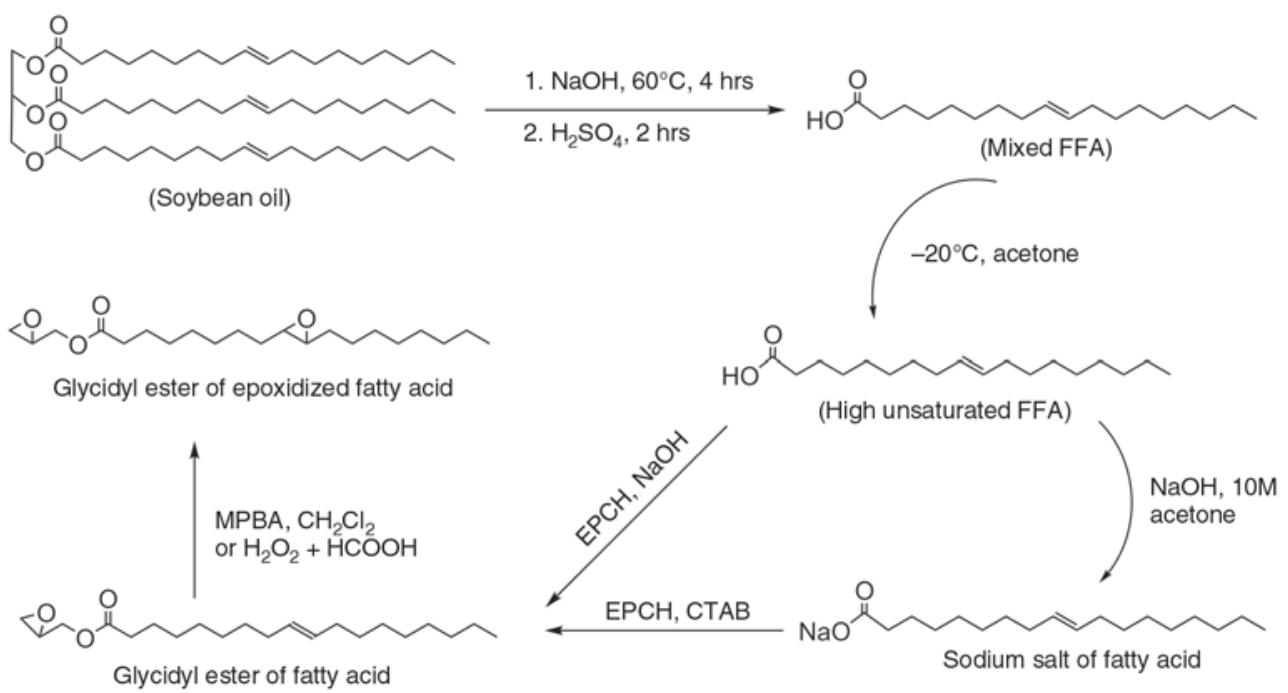

Figure 1. Synthetic route to EGS. (Vegetable oil and FAs are shown as simplified structures containing only oleic acid though they also contain other FAs. See Table 1) 
ride, large amounts of recoverable solvent was required for the epoxidation.

Figure 2 shows the FT-IR spectra of mixed FFA, soybean oil, glycidyl esters and EGS. The band at $3008 \mathrm{~cm}^{-1}$ was attributed to the $\mathrm{C}-\mathrm{H}$ stretching of $=\mathrm{CH}$ in unsaturated FAs, such as oleic acid, linoleic acid or linolenic acid. New bands at 910 and $852 \mathrm{~cm}^{-1}$ were observed in the spectrum of glycidyl esters with the disappearance of the absorption at $937 \mathrm{~cm}^{-1}$ in the mixed-FFA spectrum that showed presence of glycidyl group. The conversion of double bonds to epoxy was confirmed by the disappear-

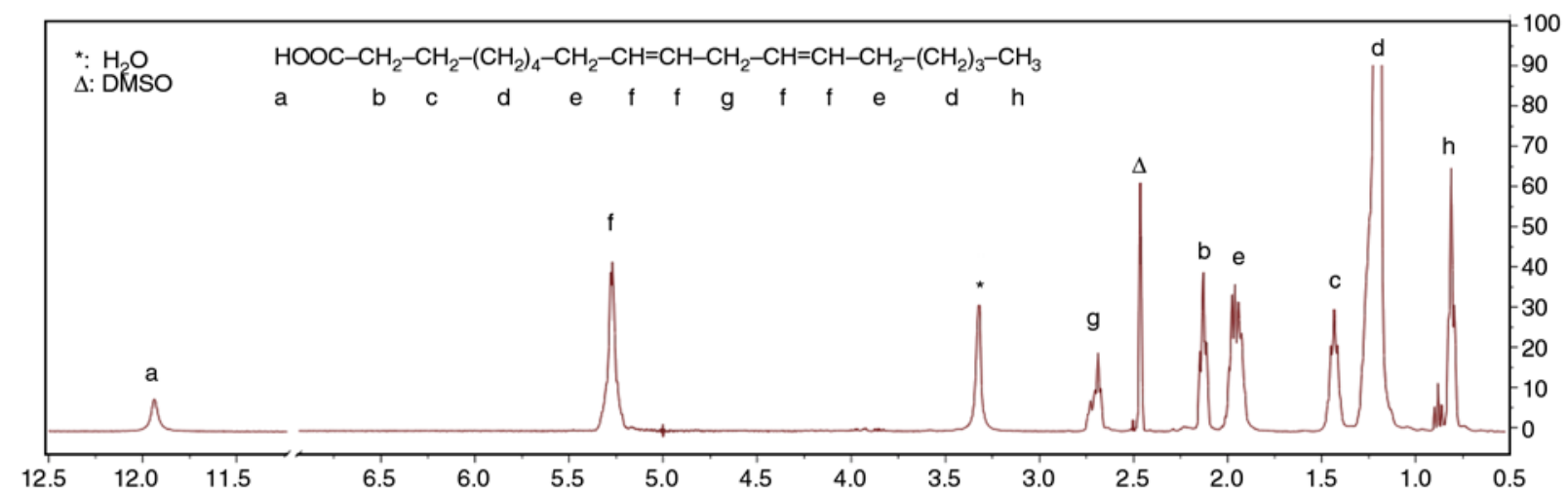

a)

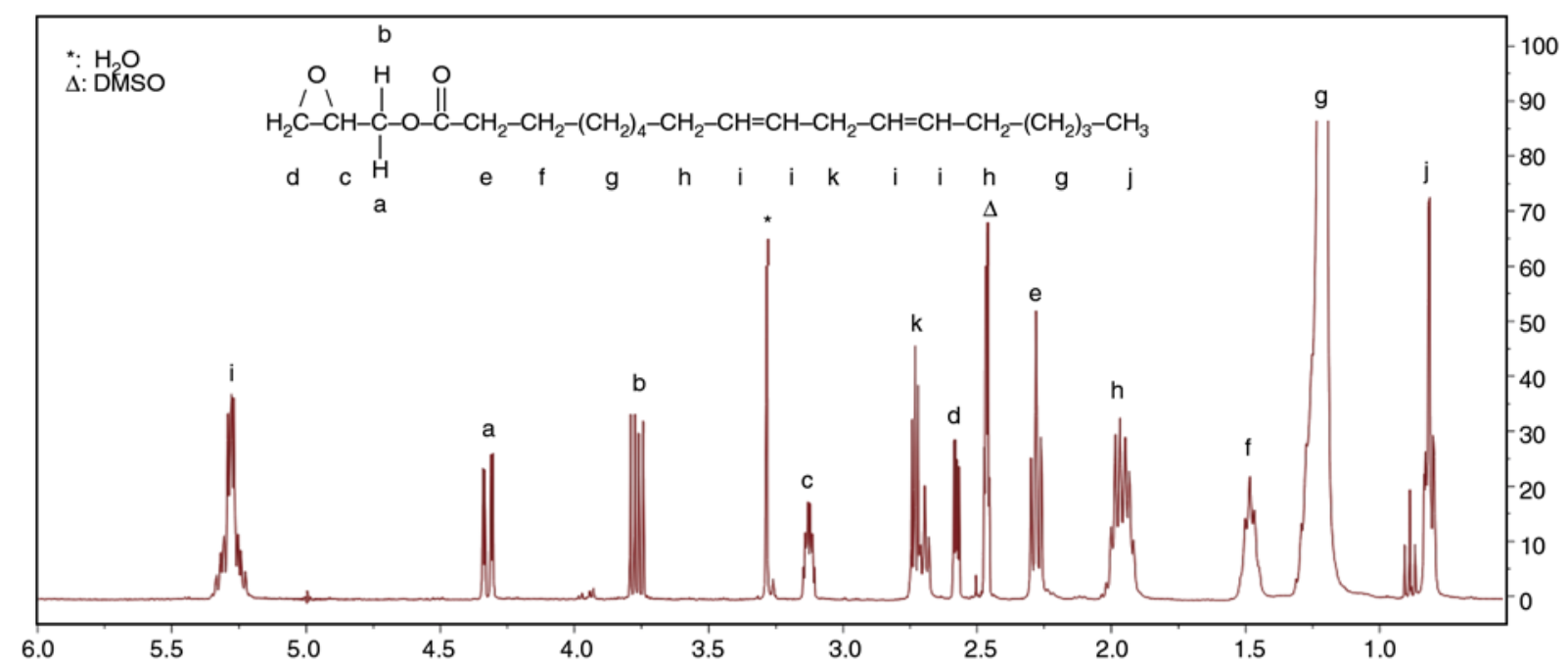

b)

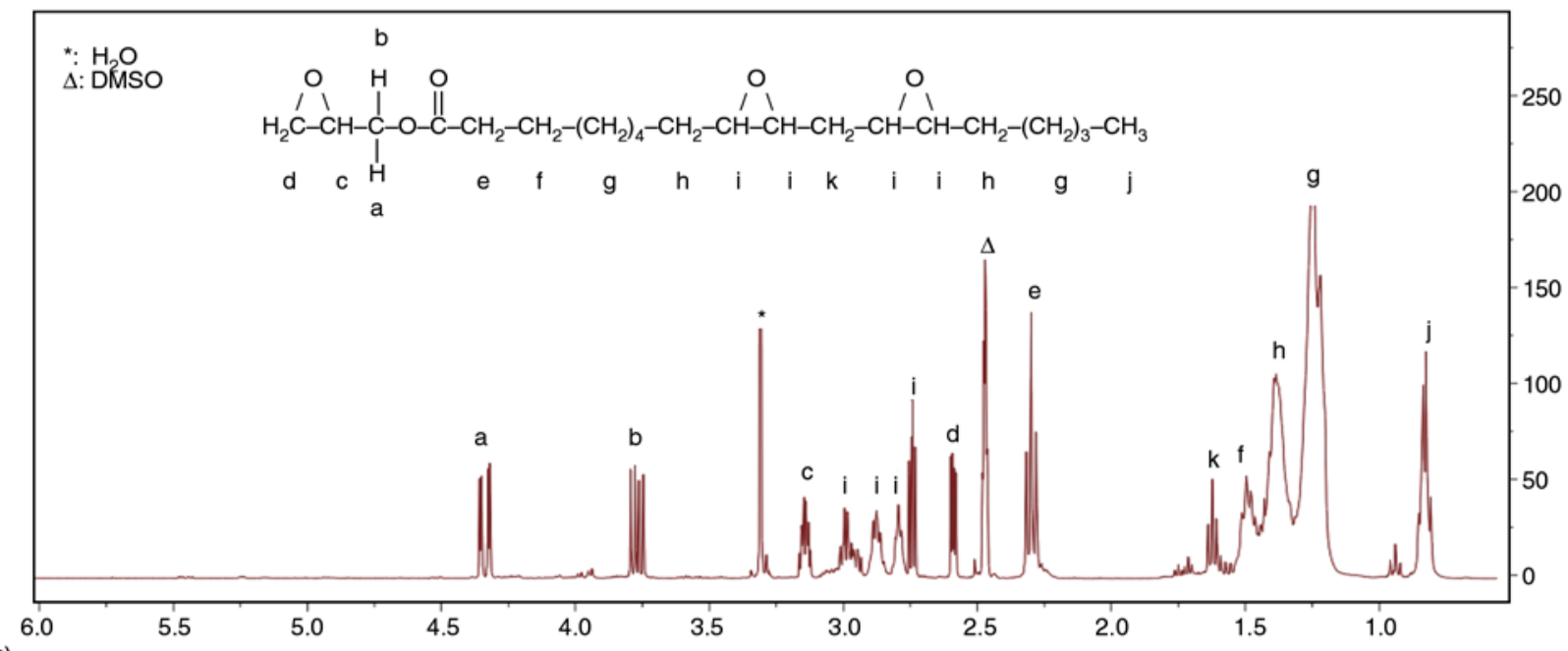

c)

Figure 3. ${ }^{1} \mathrm{H}$ NMR spectrum and structural assignments of a) FFA mixture; b) glycidyl ester of FFA mixture; and c) EGS monomer (see text for structural assignment details) 
Table 2. General physical properties of epoxy resins

\begin{tabular}{|l|c|c|c|c|}
\hline \multicolumn{1}{|c|}{ Epoxy resin } & $\begin{array}{c}\text { Oxirane oxygen } \\
\text { [g/100 g sample] }\end{array}$ & $\begin{array}{c}\text { EEW } \\
\text { [g/equivalent] }\end{array}$ & $\begin{array}{c}\text { Viscosity at 25 }{ }^{\circ} \mathbf{C} \\
{[\mathbf{m P a} \cdot \mathbf{s}]}\end{array}$ & $\begin{array}{c}\text { Density } \\
{[\mathbf{g} / \mathbf{m L}]}\end{array}$ \\
\hline EGS & 10.1 & 158 & 70 & 1.03 \\
\hline ESO & 6.9 & 232 & 430 & 0.98 \\
\hline EGL & 12.0 & 134 & 85 & 1.04 \\
\hline ELO & 9.3 & 171 & 800 & 1.03 \\
\hline DGEBA & 8.6 & 186 & 13000 & 1.16 \\
\hline
\end{tabular}

ance of the $3008 \mathrm{~cm}^{-1}$ band observed in glycidyl esters and the concurrent appearance of absorption at $752 \mathrm{~cm}^{-1}$ in EGS.

Figure 3 shows the ${ }^{1} \mathrm{H}$ NMR spectra of mixed-FFA, glycidyl ester and EGS, where linoleic acid is shown as a generalized compound for structural assignments. The spectra showed no evidence of side reactions in preparing glycidyl esters using the soap process, nearly quantitative conversion of double bonds to epoxy groups, and no oxirane ring opening during the epoxidation of glycidyl esters to EGS using MCPBA, i.e., showed complete conversion but a lack of side reactions.

General properties of EGS product compared to ESO and DGEBA is shown in Table 2.

\subsection{Curing reaction}

Differential scanning calorimetry was applied to study the curing behavior of the blended epoxy resins (Figure 4). The exothermic peaks were characteristic of the epoxy and anhydride curing reaction $[52,53]$. Integration of the peaks allows the determination of the enthalpy of curing reaction $(\Delta H)$, cure onset temperature $\left(T_{\mathrm{o}}\right)$ and peak exother$\operatorname{mic}\left(T_{\mathrm{p}}\right)$.

From Figure 4, the pure DGEBA and ESO reactions with MHHPA show single exothermic reaction peak at $152^{\circ} \mathrm{C}$ and $216^{\circ} \mathrm{C}$, respectively. The higher predominance of the $T_{\mathrm{p}}$ value of ESO means a slower reaction rate, which was also confirmed by a lower $\Delta H$ value. A lower oxirane content of ESO and the internal oxiranes versus glycidyl functional groups react more sluggishly with MHHPA curing agent.

The addition of ESO to DGEBA leads to a shifting of $T_{\mathrm{p}}$ and $T_{\mathrm{o}}$ to higher values. With a decrease of $\Delta H$ value, two partially convoluted peaks were clearly observed that became pronounced for $50 \mathrm{wt} \% \mathrm{ESO}$ or higher ESO concentrations, which suggested that there was decreasing ESO miscibility in the DGEBA. Immiscibility would lead to an inhomogeneous cure of the epoxy resin. Group reactivity also affects the polymerization reactions. ESO has internal, hindered oxiranes whereas DGEBA has glycidyl groups of less steric hindrance and greater reactivity than the internal oxirane.

The prepared EGS resin showed quite different and interesting curing behavior. The neat EGS showed two convoluted peaks, analogous to the blend of DGEBA and ESO, which is believed to be due to the inherently different reactivity of glycidyl and internal oxirane groups. The $T_{\mathrm{p}}$ and $T_{\mathrm{o}}$ values of EGS were more than $40^{\circ} \mathrm{C}$ lower than $\mathrm{ESO}$, which indicated EGS was much more reactive than ESO. Increased addition of EGS to DGEBA also lead to shifting of $T_{\mathrm{p}}$ to higher values but the $T_{\mathrm{o}}$ remained nearly constant. Only a $16^{\circ} \mathrm{C}$ increase of $T_{\mathrm{p}}$ was observed for $90 \mathrm{wt} \%$ EGS concentration compared to pure DGEBA while it was $54^{\circ} \mathrm{C}$ for a $90 \mathrm{wt} \%$ ESO concentration.

The $\Delta H$ 's $[\mathrm{J} / \mathrm{g}]$ also followed a similar trend. The higher oxirane content of EGS and EGS blends, which bear glycidyl groups like pure DGEBA, would appear to facilitate a more homogenous three dimensional polymer structure upon curing compared to ESO blends. Also of interest, a lower concentration of EGS/ESO, e.g., $30 \mathrm{wt} \% \mathrm{EGS}$ or below, or $10 \mathrm{wt} \%$ ESO, had little effect on the $\Delta H$ or $T_{\mathrm{p}}$ values compared to pure DGEBA cure, which may then be related to homogeneity and compatibility with the DGEBA.

\subsection{Compatibility}

The DGEBA-ESO system generally has a heterogeneous structure [52] and, not surprisingly, a nonuniform crosslinked structure will lead to a poorer mechanical performance compared to a more homogeneous structure. Cured aromatic DGEBA polymers are much more rigid compared to cured aliphatic ESO, which behave as weak points or flaws when applying load. Fracture is initiated by the stress concentration at weak points. For instance, the mechanical properties of soybean oil/DVB plastics are significantly improved after increasing the 


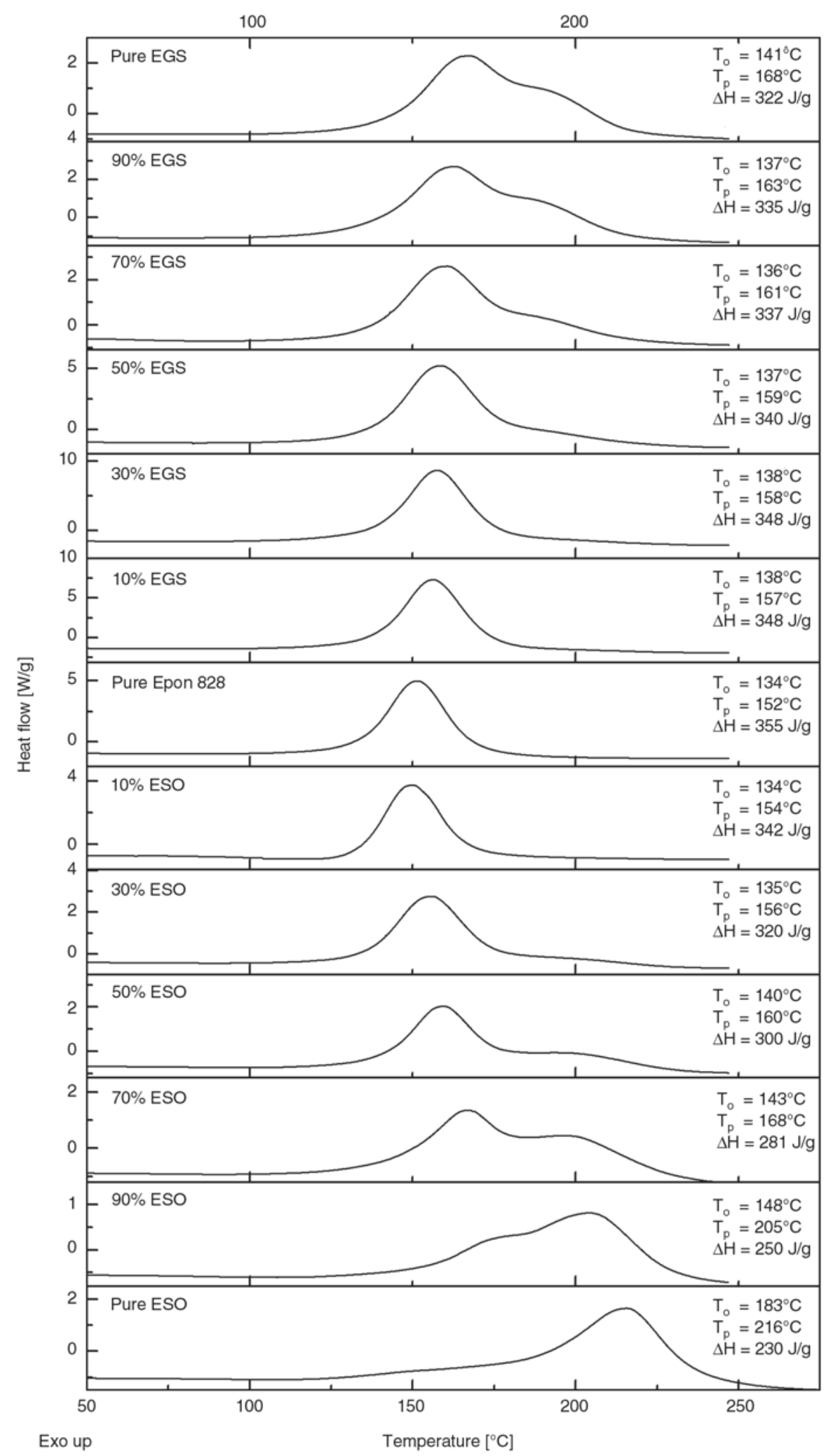

Figure 4. Dynamic thermograms of DGEBA-EGS/ESO-MHHPA systems

uniformity of the crosslinked structure [7]. A heterogeneous polymer structure is mainly due to the reactivity differences between internal and terminal oxirane. Moreover, the miscibility/compatibility between the monomer-monomer and monomer- polymer structures should also play an important role during the formation of crosslinked structure.

Solubility parameter is one method to assess the compatibility of epoxy resin with an additive or modifie [54]. To form a homogeneous structure, the 
monomers and copolymers should have similar solubility parameters in accordance with the general rule that chemical and structural similarity favors solubility, i.e., 'like dissolves like'. Direct determination of polymer solubility parameters from heat of vaporization data is not possible because of their non-volatility [55].

Thus, Hildebrand solubility parameters were calculated based on the group contribution method [56]. The group contribution equation is given by Equation (2):

$$
\delta=\frac{\rho \sum_{\mathrm{i}} F_{\mathrm{i}}}{M}
$$

where $\delta$ is the calculated solubility parameter, $\Sigma_{\mathrm{i}} F_{\mathrm{i}}$ is the molar attraction constant summation over discreet $i$ structural group present in the compound and $\rho$ and $M$ are the density and molar mass of the compound, respectively. For polymers, $\Sigma_{\mathrm{i}} F_{\mathrm{i}}$ is the sum of all the molar attraction constants in the repeat unit, $\rho$ is the density of the polymer, and $M$ is the molar mass of the repeat unit. For copolymers or polymer blends, following Equation (3) was used:

$$
\delta_{\text {mix }}=\frac{\sum_{\mathrm{i}} x_{\mathrm{i}} V_{\mathrm{i}} \delta_{\mathrm{i}}}{\sum_{\mathrm{i}} x_{\mathrm{i}} V_{\mathrm{i}}}
$$

where $x_{\mathrm{i}}$ is mole fraction of component $i, V_{\mathrm{i}}$ is component $i$ molar volume, and $\delta_{\mathrm{i}}$ is component $i$ solubility parameter. In this study, the solubility parameter of each resin was calculated based on Hoy or van Krevelen model [56]. All compounds structures are listed in Figure 5. For EGS, a total 2.3 epoxy groups were used for the calculation, which was calculated from titrated oxirane content. Calculated $\delta$ values are listed in Table 3 .

From Table 3, DGEBA, MHHPA and EGS have larger solubility parameters while ESO has the lowest solubility parameter in the blend system. Calculated values of DGEBA are close to the lower limits of the experimental values [13], which are often more reliable than upper-limit ones [57]. There are some differences in the calculated values using Hoy versus van Krevelen models because epoxy group and ether group have different values in Hoy's model. Epoxy groups should convert to ether/ester after<smiles>CCCCCC1OC1CC1OC1CCCCCCCCC(=O)OCC1CO1</smiles><smiles>CC(C)(c1ccc(OCC2CO2)cc1)c1ccc(OC(C)(C)C(C)(C)c2ccc(OCC(O)C(C)(C)c3ccc(OCC4CO4)cc3)cc2)cc1</smiles>

DGEBA

$(E E W=186)$<smiles>CC1CCC2C(=O)OC(=O)C2C1</smiles>

MHHPA

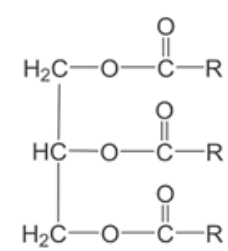

ESO

where $\mathrm{R}$ is epoxidized fatty acid chain

Figure 5. Compounds structure used for solubility parameters calculation

Table 3. Calculated solubility parameters of monomer and cured matrix

\begin{tabular}{|l|c|c|c|c|c|c|c|}
\hline $\begin{array}{c}\boldsymbol{\delta} \\
{\left[\mathbf{M P a}^{\mathbf{1} / \mathbf{2}}\right]}\end{array}$ & EGS & DGEBA & ESO & MHHPA & DGEBA-MHHPA & EGS-MHHPA & ESO-MHHPA \\
\hline$\delta($ van Krevelen) & 17.8 & 20.5 & 17.5 & 18.2 & 19.4 & 18.0 & 17.8 \\
\hline$\delta$ (Hoy) $^{*}$ & $\begin{array}{c}19.5 \\
(18.6)\end{array}$ & $\begin{array}{c}21.9 \\
(21.1)\end{array}$ & $\begin{array}{c}19.0 \\
(18.4)\end{array}$ & 20.9 & 21.0 & 19.4 & 19.7 \\
\hline
\end{tabular}

*Values in brackets are calculated based on linear ether functional group instead of cyclic oxirane. 
curing reaction, so values based only on ether groups instead of epoxy were also listed in Table 3 . There is a considerable difference in the values of MHHPA due to the large difference between the group contributions of the anhydride group quoted by Hoy and by van Krevelen. Only van Krevelen values were used for the further calculation because there is evidence showing experimental values matched well with van Krevelen calculated values in the DGEBA-anhydride system [58].

It has been reported that ESO [59] or pre-polymerized ESO [60] is only partially miscible, i.e., has phase separation, with the epoxy resins. The thermodynamic condition for polymer compatibility is that free energy change of mixing $\left(\Delta G_{\text {mix }}\right)$ should be small or negative, based on Flory-Huggins equation combined and Hildebrand solubility parameters [61]. $\Delta G_{\text {mix }}$ can be expressed by Equation (4):

$$
\begin{aligned}
\Delta G_{\text {mix }} & =\phi_{1} \phi_{2} V\left(\delta_{1}-\delta_{2}\right)^{2}+ \\
& +R T V\left(\frac{\phi_{1} \rho_{1}}{M_{1}} \ln \phi_{1}+\frac{\phi_{2} \rho_{2}}{M_{2}} \ln \phi_{2}\right)
\end{aligned}
$$

where $\phi_{\mathrm{n}}$ is the phase volume fraction, $V$ is volume of lattice, $\rho_{\mathrm{i}}$ is the density of component $i, M_{\mathrm{i}}$ is the molecular weight of component $i, R$ is gas constant and $T$ is absolute temperature. The first term of the right side in Equation (4) is related to the enthalpy of mixing $\left(\Delta H_{\text {mix }}\right)$ and the second term is assigned to the entropy of mixing $\left(-T \Delta S_{\text {mix }}\right)$. Since $\phi_{1}$ and $\phi_{2}$ are fractions, for a fixed DGEBA-EGS/ESO composition, $\Delta G_{\text {mix }}$ at constant temperature depends only on $\Delta \delta_{\mathrm{i}}$ and $\rho_{\mathrm{i}} / M_{\mathrm{i}}$, which are determined by the chemical nature and molecular weight of the EGS/ ESO/DGEBA, respectively. Proximity of $\delta_{\mathrm{i}}$ between DGEBA and EGS/ESO and a low molecular weight EGS/ESO favors the mixing process. It is not then surprising that EGS of higher solubility parameter and lower molecular weight favors better compatibility with DGEBA than ESO.

We have noticed turbid blends indicating phase separation were formed only for high contents of DGEBA replacement by ESO (90 and $100 \mathrm{wt} \%$, Figure $6 \mathrm{~b}, 6 \mathrm{c}$ and $6 \mathrm{~d}$ ), especially when using EMI as accelerator. While using tertiary amine a more transparent solution was formed but tertiary amine generally lead to lower $T_{\mathrm{g}}$ compared to using imidazole as accelerator [53]. These blends were prone to form cracked samples after curing and spots with dark brown or yellow colors were also observed

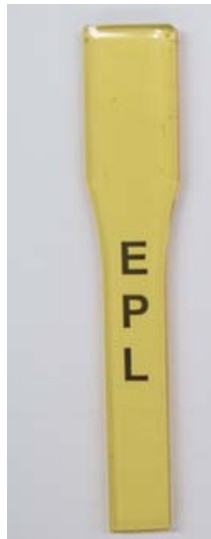

(a)

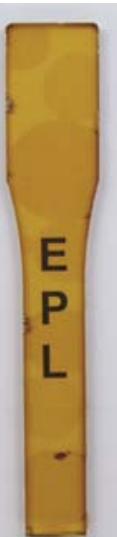

(b)

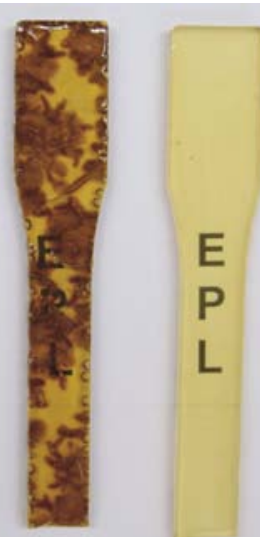

(c) (d)

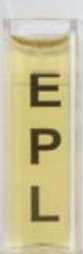

(a)

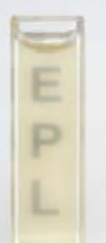

(b)

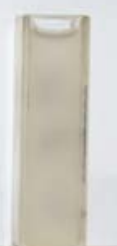

(c)

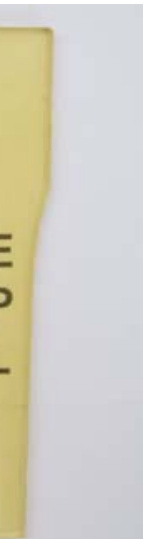

Figure 6. Physical appearances of MHHPA cured EGS/ESODGEBA polymers and uncured monomers blends (a): EGS-DGEBA (90:10); (b): ESO-DGEBA (90:10) precured at $145^{\circ} \mathrm{C}$ for $10 \mathrm{~min}$; (c): ESODGEBA (90:10) without procuring; (d): Pure ESO inducted for $12 \mathrm{hrs}$

(Figure $6 \mathrm{~b}$ and $6 \mathrm{c}$ ). We ascribed these to phase separation and internal stress due to incompatibility and low reactivity of ESO in these curing systems.

The terminal oxirane of DGEBA is more reactive than the internal oxirane of ESO so gelation always occurs first in the DGEBA phase. At low ESO concentration, ESO is firstly dissolved and plasticizes the rigid DGEBA matrix but is finally cured by anhydride and becomes part of the crosslinked structure as two phase thermoset polymer. At high curing temperatures, the $\Delta G_{\text {mix }}$ is marginally negative and ESO is better compatible with DGEBA but slower to react. With the advancement of curing reaction the molecular weight of crosslinked DGEBA and ESO will increase, which will result in a decrease of $\Delta S_{\text {mix }}$. At a certain stage $\Delta G_{\text {mix }}$ becomes positive and crosslinked ESO phase separates, which should be analogous to a phase separation of rubber in epoxy resin [62].

At higher ESO concentrations, due to a faster gelation rate of the glycidyl-DGEBA network occurring at low degree of conversions of ESO, internal stress can result after vitrification but which can be avoided by proper cure temperature profile [63]. Such internal stress and incompatibility can easily 
lead to crack initiation or defect structure as observed in Figure 6c. Prolonged induction via heated mixing of the ESO blend and carefully choosing the curing conditions led to more transparent polymers and uncracked samples that were used for further testing.

For EGS blends, due to the terminal oxirane as in DGEBA, EGS may remain part of the DGEBA matrix during curing where a more homogeneous crosslinked structure is formed. An increase in oxirane value in EGS also boosts compatibility with the DGEBA system and may yield cured products with improved properties.

\subsection{Crosslink density}

Crosslink density is one of the most important factors determining the properties of cured thermoset resins and is typically reported as an average molecular weight $\left(M_{\mathrm{c}}\right)$ between crosslinks. The crosslink density increases as $M_{\mathrm{c}}$ decreases. Several methods are available for measuring the crosslink density of a thermoset. A common method is to measure the elastic modulus of the thermoset in the rubbery plateau region using dynamic mechanical analysis (DMA). Solvent swelling measurements are also used to determine the crosslink density of epoxy resin $[47,64,65]$. Good agreement between $M_{\mathrm{c}}$ values from the swelling measurements based on the stoichiometry considerations has been reported [66].

A structure based on a stoichiometric curing condition was assumed because the dominant reaction in the present epoxy-anhydride-imidazole system is esterification while etherification of epoxy groups is much slower [67]. The $M_{\mathrm{c}}$ of the cured resin was calculated from equilibrium solvent swelling data based on the Flory-Rehner equation [47] (Equation (5)):

$\nu=\frac{\rho_{\text {poly }}}{M_{\mathrm{c}}}=\frac{\ln \left(1-\nu_{2}\right)+\nu_{2}+\chi \nu_{2}}{V_{1}\left(\frac{\nu_{2}}{2}-\nu_{2}^{\frac{1}{3}}\right)}$

where $v$ is the strand density, $v_{2}$ is the volume fraction of polymer at equilibrium swelling as measured by swelling test (Equation (1)), $V_{1}$ is the molar volume of the solvent, and $\chi$ is the polymer-solvent interaction parameter, which is related to the solubility parameters via Equation (6):

$\chi=0.34+\frac{V_{1}}{R T}\left(\delta_{1}-\delta_{2}\right)^{2}$

where $R$ is the gas constant, $T$ is the absolute temperature, $V_{1}$ is the molar volume of the solvent, and $\delta_{1}$ and $\delta_{2}$ are the solubility parameters of solvent and polymer, respectively. $\delta_{2}$ was calculated by Equation (3), and where for toluene $\delta_{1}=18.3 \mathrm{MPa}^{1 / 2}$. The calculated and experimental results are listed in Table 4.

In ESO or EGS, the epoxy crosslink sites in the FA chains are located at the $9^{\text {th }}$ and $10^{\text {th }}$ carbons in the oleic acid and could be also at the $12^{\text {nd }}$ and $13^{\text {th }}$ carbons in linoleic acid, which leave the rest of the chain up through $18^{\text {th }}$ carbon as an ineffective chain end in the crosslinked polymer (Figure 7). Furthermore, the presence of saturated palmitic or stearic acids in ESO triglyceride structure also behave like pendant chain [42], so the inactive parts, e.g., pendant chains and saturated FAs, in ESO and EGS constitute 34.8 and $18 \%$ of total mass, respectively. These maybe subtracted from the dry and swollen sample weights to obtain a corrected $M_{\mathrm{c}}{ }^{*}$, because

Table 4. Swelling properties of cured epoxy resins in toluene

\begin{tabular}{|l|c|c|c|c|c|c|}
\hline $\begin{array}{c}\text { MHHPA cured } \\
\text { samples }\end{array}$ & $\begin{array}{c}\boldsymbol{\delta} \\
{\left[\mathbf{M P a}^{\mathbf{1} / \mathbf{2}}\right]}\end{array}$ & $\begin{array}{c}\mathbf{\rho}_{\text {poly }} \\
{[\mathbf{g} / \mathbf{m L}]}\end{array}$ & $\begin{array}{c}\mathbf{Q} \\
\text { Swelling ratio }\end{array}$ & $\boldsymbol{\chi}$ & $\begin{array}{c}\mathbf{M}_{\mathbf{c}} \\
{[\mathbf{g} / \mathbf{m o l}]}\end{array}$ & $\begin{array}{c}\mathbf{M}_{\mathbf{c}}{ }^{*} \\
{[\mathbf{g} / \mathbf{m o l}]}\end{array}$ \\
\hline Pure DGEBA & 19.4 & 1.18 & 1.49 & 0.388 & 257 & 257 \\
\hline EGS-DGEBA (10:90) & 19.2 & 1.17 & 1.50 & 0.375 & 253 & 256 \\
\hline EGS-DGEBA (30:70) & 18.9 & 1.16 & 1.54 & 0.356 & 268 & 278 \\
\hline EGS-DGEBA (50:50) & 18.6 & 1.16 & 1.57 & 0.345 & 281 & 299 \\
\hline EGS-DGEBA (70:30) & 18.4 & 1.15 & 1.61 & 0.340 & 304 & 330 \\
\hline EGS-DGEBA (100:0) & 18.0 & 1.12 & 1.66 & 0.344 & 332 & 376 \\
\hline \multicolumn{7}{|l|}{} \\
\hline ESO-DGEBA (10:90) & 19.3 & 1.17 & 1.51 & 0.375 & 261 & 267 \\
\hline ESO-DGEBA (30:70) & 19.0 & 1.15 & 1.55 & 0.355 & 273 & 293 \\
\hline ESO-DGEBA (50:50) & 18.6 & 1.14 & 1.58 & 0.343 & 285 & 324 \\
\hline ESO-DGEBA (70:30) & 18.3 & 1.12 & 1.64 & 0.340 & 314 & 382 \\
\hline ESO-DGEBA (100:0) & 17.8 & 1.09 & 1.84 & 0.350 & 464 & 640 \\
\hline
\end{tabular}




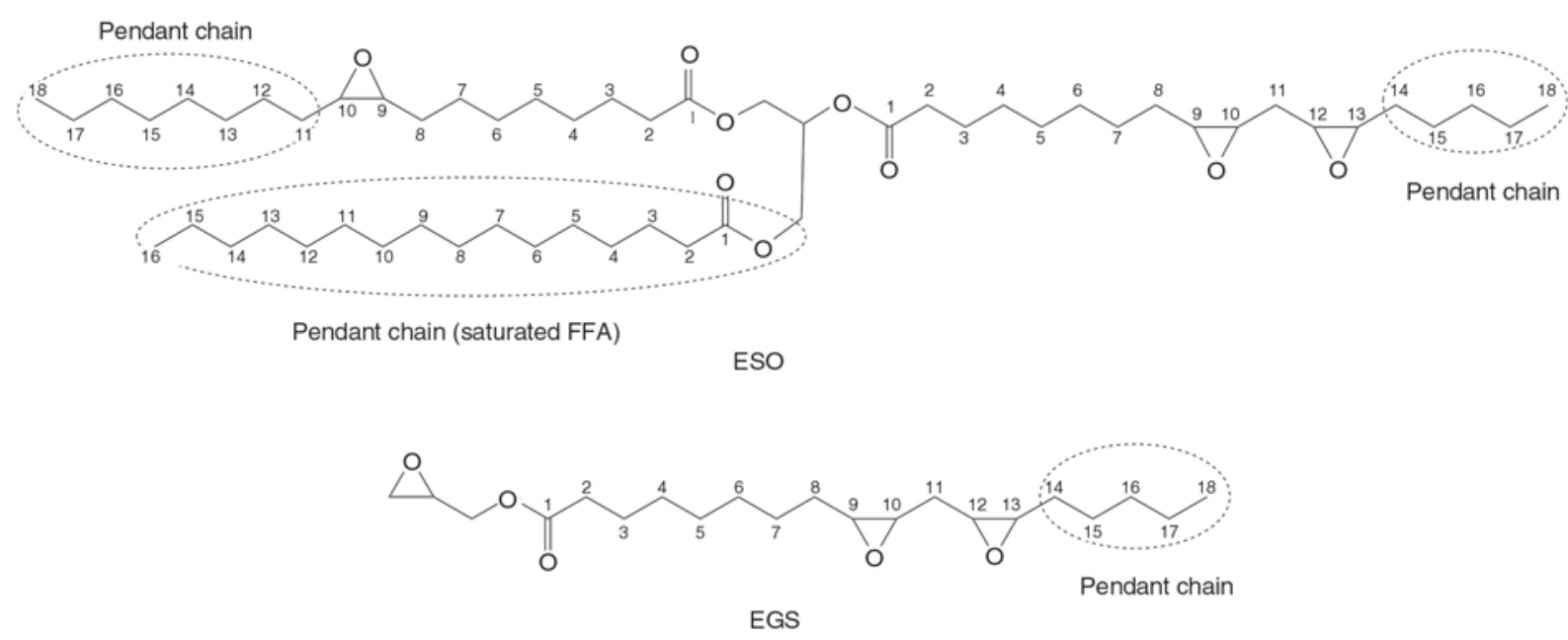

Figure 7. Schematic representation of pendant chain in ESO structure (epoxy moieties in ESO/EGS and methane moiety in glycerol part of ESO are the crosslink sites)

end-linked networks were assumed during swelling test, in fact pendant chains are not contributed to the total crosslink densities [38]. $M_{\mathrm{c}}$ and corrected $M_{\mathrm{c}}{ }^{*}$ values are listed in Table 4.

From Table 4, the $\rho$ values of both EGS and ESO systems decrease with the increase of EGS/ESO content that can be attributed to the addition of a large soft/flexible vegetable oil component to decrease the rigid, compact structure of DGEBA polymer. Increase in EGS/ESO content also leads to a higher swelling ratio $Q$, which could indicate not only lower crosslinking density but also a higher solubility of the network in the toluene solvent that is supported by a decreased $\chi$ value. $M_{\mathrm{c}}$ and $M_{\mathrm{c}}{ }^{*}$ values of MHHPA cured neat DGEBA [68] and neat ESO [31] are similar to reported DMA test results. Pure EGS, which has similar oxirane content as ELO, also is close to a reported DMA test result for polymerized ELO [53]. Calculated values based on the van Krevelen model are also comparable to DMA tests.

In general, an increase in ESO or EGS content decreased crosslink density compared to a neat anhydride cured DGEBA. This result is due to the inherently flexible structure of fatty acid chain and thereby prone to form a less compact crosslinked structure compared to the stiffer aromatic repeat unit of DGEBA. A decrease in crosslink density was also reported by others [20].

Crosslink density is also related to the oxirane value. EGS has higher oxirane value than ESO so all EGS blends had higher crosslink densities compared to ESO blends at the same concentration level. Crosslinking density increasing with oxirane value has also been observed within various EVOs of different oxirane content [69] or for the same vegetable oil with different oxirane content [16]. Surprisingly, $10 \mathrm{wt} \%$ EGS concentration had a similar crosslink density as pure DGEBA, which is in part probably due to a higher functionality of EGS compared to pure DGEBA. More anhydride needed to cure the blend would lead to higher crosslink densities. With increases in the EGS content in blends, a lower crosslink density was observed though the crosslink density had minimal change even at $50 \mathrm{wt} \%$ concentration. ELO has similar epoxy content as EGS and has been reported to maintain nearly constant crosslink density of the anhydride-cured epoxy at up to $70 \mathrm{wt} \%$ concentration [70]. For ESO with much lower oxirane value compared to DGEBA or EGS, the crosslink density of ESO blends decreased with increased ESO concentration that is especially noticeable after $M_{\mathrm{c}}$ correction for pendant chains. The saturated component in ESO thus plays a significant role in reducing the crosslink density. Though crosslink density has been reported to not be changed by the replacement of DGEBA by ESO using mechanical analysis of the rubbery plateau [52], an artificially larger modulus can result for the inherently heterogeneous DGEBA-ESO-anhydride network due to a broadened glass transition temperature range. As heterogeneity will broaden the modulus signal in the rubbery region, a shear storage modulus value near the glass transition in the rubbery region can be artificially increased resulting in an inflated value for the calculated crosslink density. 


\subsection{Thermal properties}

The glass transition temperature $\left(T_{\mathrm{g}}\right)$ is considered a fundamental polymer characteristic related to polymer properties and processing. In general, polymers with high crosslink density have higher $T_{\mathrm{g}}$; however, the composition in the polymer within the crosslinked structure also plays an important role in the $T_{\mathrm{g}}$ behavior. DSC and DMA are widely used to characterize $T_{\mathrm{g}}$. For most thermosetting plastics, the DMA measurement based on the $\tan \delta$ peak at a frequency of $1 \mathrm{~Hz}$ generally occurs at a temperature as much as $15-20^{\circ} \mathrm{C}$ above $T_{\mathrm{g}}$ as measured by dilatometry or DSC $[16,26]$ but inflection temperature typically correlate better with DMA $\tan \delta$ than a midpoint value.

The trend of cured epoxy resin blends (polymers) $T_{\mathrm{g}}$ as measured by DSC is shown in Figure 8 . The MHHPA cured pure EGS had higher $T_{\mathrm{g}}\left(88^{\circ} \mathrm{C}\right)$ which was nearly $40^{\circ} \mathrm{C}$ higher than ESO-MHHPA. Pure DGEBA-MHHPA polymers which is aromatic and had the highest $T_{\mathrm{g}}$ measured $\left(152^{\circ} \mathrm{C}\right)$. Aliphatic amine $[12,71]$, or boron trifluoride diethyl etherate $[72,73]$, cured ESO polymers had low $T_{\mathrm{g}}$, usually less than $0^{\circ} \mathrm{C}$. While aromatic amine [29], cycloaliphatic amine [74], thermally latent initiator [75], or anhydride [76] cured EVO polymers generally have higher $T_{\mathrm{g}}$, it is still rare to observe cured ESO polymers [31,77] with $T_{\mathrm{g}}$ above $60^{\circ} \mathrm{C}$.

Addition of ESO or EGS led to a decrease of $T_{\mathrm{g}}$. For small EGS/ESO concentration, e.g., below $30 \mathrm{wt} \%$, the $T_{\mathrm{g}}$ values of ESO-DGEBA or EGS-DGEBA systems were quite similar to each other and slightly decreased compared to pure DGEBA-MHHPA, which indicated the $T_{\mathrm{g}}$ behavior was mainly determined by the crosslink density as measured in the swelling test where only slight increases of $M_{\mathrm{c}}$ or
$M_{\mathrm{c}}{ }^{*}$ were observed. However, the aromatic DGEBA versus aliphatic EGS structure also plays a role because $10 \mathrm{wt} \%$ EGS concentration appears to have a slightly higher crosslink density but still a lower $T_{\mathrm{g}}$. It has been reported that aromatic phthalic anhydride cured EVO had higher $T_{\mathrm{g}}$ but lower crosslink density [31, 53].

For further increases in the concentration of EGS/ ESO, the $T_{\mathrm{g}}$ values decreased more rapidly, especially for the ESO system. The inherent, long aliphatic chain structure of ESO, sluggish reactivity of internal oxirane, and lower oxirane content preclude polymer as densely crosslinked as those of EGS or DGEBA. Unreactive saturated components like stearic acid and palmitic acid pendant chains enhance the flexibility and degree of freedom for movements of the molecular chains in the epoxy network. These factors decrease the polymer $T_{\mathrm{g}}$. Further depressed $T_{\mathrm{g}}$ was also reported for an epoxidized palm oil system, which had lower oxirane content than ESO [26].

At low ESO concentrations $(\leq 50 \mathrm{wt} \%)$ a linear, decreasing $T_{\mathrm{g}}$ trend was observed, however, neat ESO or higher ESO concentrations ( $\geq 50 \mathrm{wt} \%$ ) thermosetting polymers showed broad transitions from the glassy to the rubbery state. The blends' $T_{\mathrm{g}}$ seems predominately controlled by the ESO part. Similar behavior was also found in ELO replacement of diglycidyl ether of bisphenol F resin [78]. The plasticizing effect of saturated FAs and/or the different reactivity of ESO and DGEBA leads to a broad distribution of chain segment mobilities [79] and indicate a heterogeneous polymer network [80]. Broad $T_{\mathrm{g}}$ range behavior was not found in the EGSDGEBA systems. Also a nearly linear transition of $T_{\mathrm{g}}$ with increase of EGS was observed, which indi-
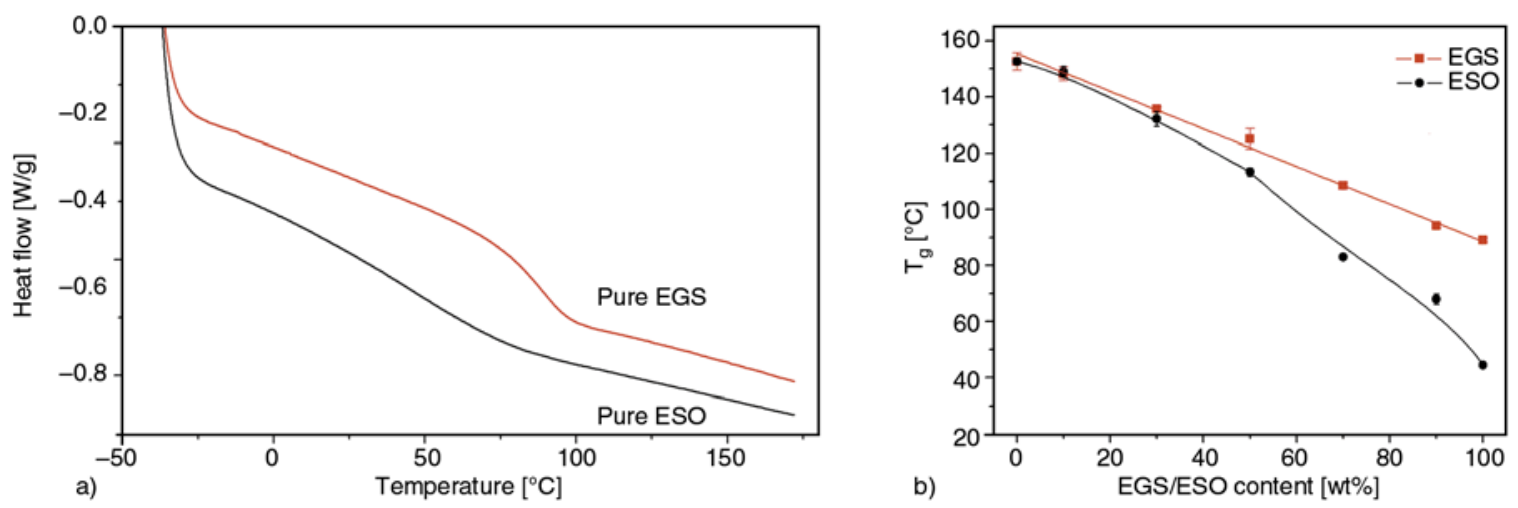

Figure 8. Plots of a) the glass transition region of ESO/EGS-MHHPA neat polymer showing the differences in breadth of the transition; b) the measured inflection point glass transition temperatures of cured epoxy monomer(s) as a function of ESO/EGS-DGEBA blend composition (Lines only to aid visualization of trend) 


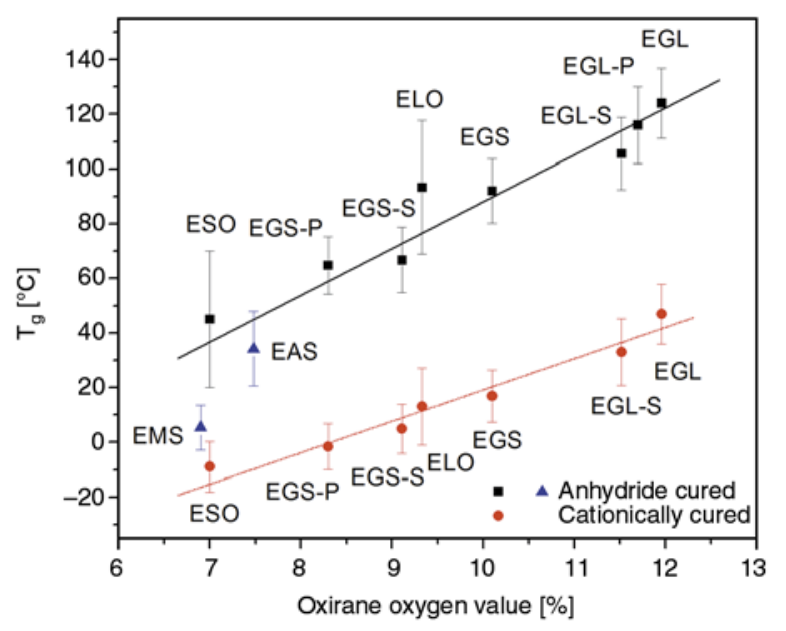

Figure 9. Polymer glass transition temperatures as a function of monomer oxirane contents through cationic homopolymerization and MHHPA copolymerization. [Note: straight lines are to indicate trend; vertical bars indicate the breadth of glass transition region equal to the difference between onset temperature and endset temperature as determined in DSC].

cated good synergy and homogeneity of the crosslink structure formation between EGS and DGEBA.

Researchers $[16,69]$ have noted the influence of EVO monomer oxirane value on polymer $T_{\mathrm{g}}$. We present trends in relationship between $T_{\mathrm{g}}$ and EVO structure with and without saturated components. Several epoxy resins made from vegetable oils were synthesized and polymerized by MHHPA with EMI as catalyst and/or cationically polymerized with $\mathrm{BF}_{3}$-MEA initiation. The obtained plot of polymer $T_{\mathrm{g}}$ as a function of oxirane oxygen value is presented in Figure 9.

The glass transition temperatures of anhydride cured copolymers are higher than those of the neat of cationically cured monomers due to the anhydride structural stiffness elevating the copolymer $T_{\mathrm{g}}$. The $T_{\mathrm{g}}$ are observed to increase fairly linearly with oxirane value. Higher oxirane values are expected to lead to higher crosslink densities upon curing. A similar $T_{\mathrm{g}}$ for anhydride cured ELO and EGS was observed though ELO has a slightly lower oxirane value. The ELO structure is partially crosslinked, i.e., glycerol crosslinks the three FFAs, and would have a slightly higher oxirane value if converted to the glycidyl structure like EGS. Linseed oil is also richer in linolenic acid content that may facilitate a dense crosslinked structure.
EGS and EGL have much higher $T_{\mathrm{g}}$ compared to their respectively ESO or ELO counterparts. A $T_{\mathrm{g}}$ value of $124^{\circ} \mathrm{C}$ was measured for EGL, which appears unprecedented for a vegetable oil based thermoset polymer. The $T_{\mathrm{g}}$ increases in EGS-S/ EGS-P and EGL-S/EGL-P are mainly due to the addition of the reactive glycidyl group compared to ESO and ELO. Removal of the saturated components greatly increases the $T_{\mathrm{g}}$. A 30 and $20^{\circ} \mathrm{C}$ increase in polymer $T_{\mathrm{g}}$ was observed for MHHPA cured EGS and EGL compared to EGS-S and EGL-S, respectively. Such trends are observed in the $M_{\mathrm{c}}$ calculations as a significant increase of crosslink density upon exclusion of the saturated components.

Adding an unreactive function group, e.g., allyl (EAS) or methyl groups (EMS), generates a lower $T_{\mathrm{g}}$ though the oxirane values are similar to that of ESO. Since the allyl group in EAS is partially epoxidized, EAS has even slightly higher oxirane value than ESO. The $T_{\mathrm{g}}$ 's are greatly decreased compared to ESO because, unlike ESO that is partially crosslinked through glycerol, transesterification engenders all the fatty acid carbons except carbons in the epoxy groups into pendant chains. In addition, the liberated saturated FFA esters behave as plasticizers in the matrix to increase the chain segment mobility and decrease crosslink density. Monofunctional epoxidized methyl oleate and epoxidized oleic acid have lower oxirane content compared to EMS and were difficult to polymerize by our current curing conditions though polymer $T_{\mathrm{g}}$ of -14 to $-50^{\circ} \mathrm{C}$ have been reported $[36,81]$.

Broader $T_{\mathrm{g}}$ regions (onset-endset ranges are provided in Figure 9 using bars; NOTE: the vertical bars are not 'error' bars or deviations but indicate the measured temperature range breadth of the glass transition) indicate a broader distribution of chain environments and heterogeneous structures were observed in anhydride cured ELO and ESO. We ascribe the less homogenous polymer structures to a low reactivity of internal oxirane in ELO or ESO instead of saturated components because even EGS-S and EGL-S with saturated FFAs show relatively sharp glass transition ranges. Indeed, internal epoxy is more reactive in cationic polymerization where all epoxies show a similar transition breadth when initiated by $\mathrm{BF}_{3}$-MEA. EMS of all internal oxirane structure and saturated FFA also show a narrow glass transition region, which could be due 


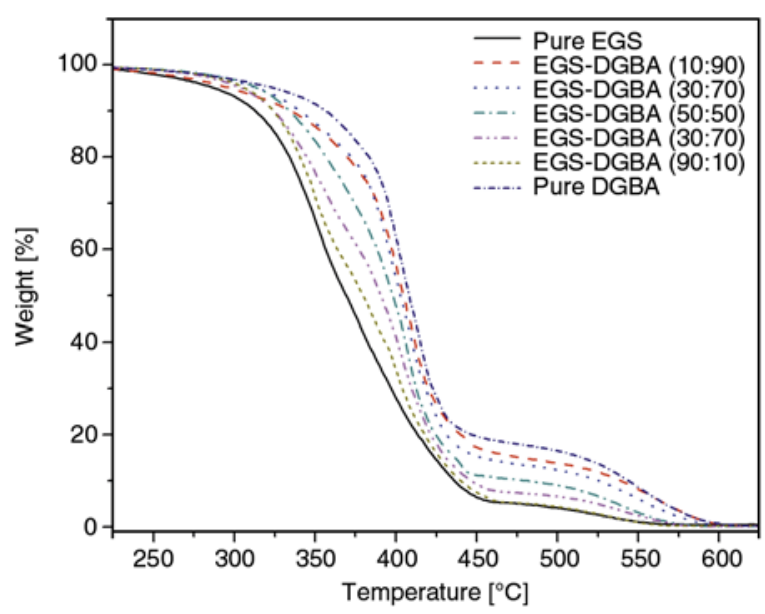

Figure 10. TGA of MHHPA cured EGS-DGEBA blends compared to pure EGS and pure DGEBA

to greater reactivity of the small molecules during curing compared to large oligomers of ESO or ELO [37].

Figure 10 presents the TGA weigh loss as a function of temperature curves for the polymerized epoxy resin. Since the ESO-DGEBA blend had a similar thermal stability as the EGS-DGEBA blend, only the latter is shown here. TGA results indicated all cured EGS-DGEBA resins appear thermally stable to temperatures at least $300^{\circ} \mathrm{C}$. Replacements of DGEBA by EGS led to an earlier onset of degradation. All epoxies presented two stage degradation behavior. The first stage of decomposition from 300 to $450^{\circ} \mathrm{C}$ is believed to be due to decomposition of unreacted MHHPA, dehydration of hydroxyl groups, and the pyrolysis of the crosslinked epoxy resin network. The second stage loss from $\sim 450$ to $600^{\circ} \mathrm{C}$ was considered to be the complete decomposition of the smaller fragments like cyclized or aromatic degradation byproducts as indicated by the decrease of char residue when EGS component was increased.

\subsection{Mechanical performance}

Flexural and tensile properties of the polymerized resin systems as a function of ESO/EGS content were determined. The results are shown in Figures 11 and 12. Smaller concentrations of EGS led to only minor changes in strength or modulus compared to neat DGEBA. An improvement in flexural modulus was observed for $10 \mathrm{wt} \%$ EGS. Similar results, showing improved modulus at low replacement concentrations, have also been reported for an amine cured, soy-based epoxy resin system [35]. These data correlate with minor changes of $M_{\mathrm{c}}$ cal-

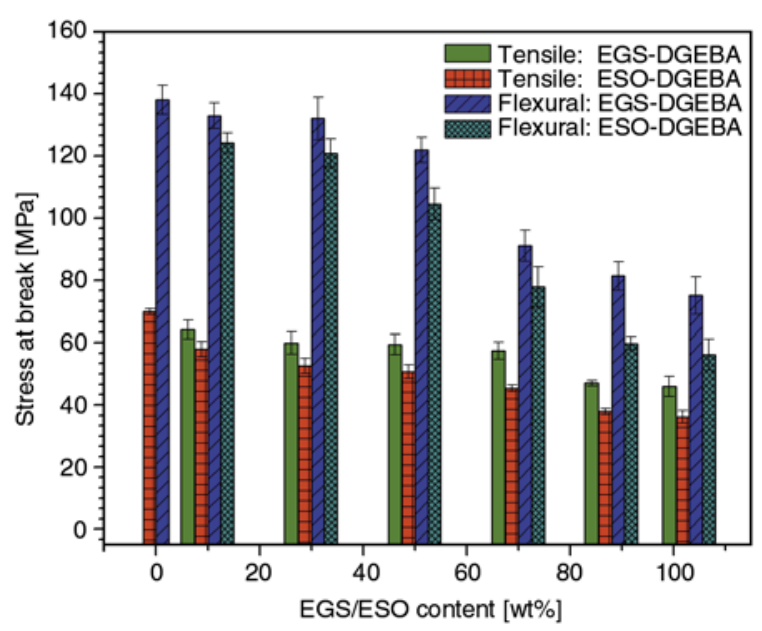

Figure 11. Tensile and flexural strengths of MHHPA and EGS/ESO-DGEBA blend copolymerization products

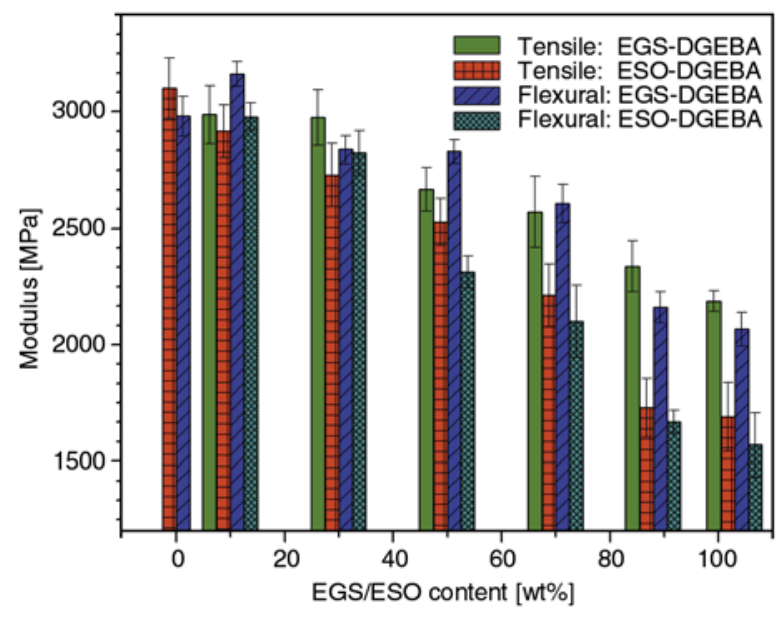

Figure 12. Tensile and flexural moduli of MHHPA and EGS/ ESO-DGEBA blends copolymerization products

culated at low concentrations of EGS/ESO in DGEBA system blends.

However, the modulus and strength values of the blends systematically decreased with further increases in ESO/EGS concentration. These phenomena are readily explained by a decrease of stiffer, bulky aromatic group content and a decreased crosslinking density of the cured blends. All the EGS-DGEBA blends showed higher strength and modulus than the ESO-DGEBA blends of comparable concentration, which is supported by smaller $M_{\mathrm{c}}$ or $M_{\mathrm{c}}{ }^{*}$ of EGS compared to ESO. The flexural stress and modulus of EGS-DGEBA exhibited a gradual decrease until $50 \mathrm{wt} \%$ followed by a more abrupt change. For ESO-DGEBA, large materials property losses occurred at $\geq 30 \mathrm{wt} \%$. The study of ref [35] studied compositions only up to $30 \mathrm{wt} \%$ soy epoxy resin. Similarly, the tensile strength of EGS-DGEBA 
had only minor changes up to $70 \mathrm{wt} \%$ concentration whereas a continuous decrease in strength was observed for ESO-DGEBA blends. As observed in Figures 4 and 6, EGS was observed to be more reactive and compatible with DGEBA and a higher content of EGS was achieved with greater homogeneity than comparable ESO blends and greater mechanical strengths.

\subsection{Viscosity reducing ability}

Reactive diluents are used for reducing and controlling the viscosity of epoxy resins to improve wetting and handling characteristics because in the liquid-molding technologies like resin transfer molding or pultrusion, the viscosity and resin flow are critical to achieving a quality laminate [82]. Recent trends toward lower volatile organic compounds (VOC), higher solids epoxy formulations have also resulted in increased utilization of reactive diluents [83]. It was found that EGS had inherently lower viscosity than ESO. EGS has an extra glycidyl group and lower molecular weight compared to ESO, which is a triglyceride and has oligomeric behavior. The viscosity reducing abilities of EGS and ESO were compared at different concentrations of replacement of the DGEBA resin, which had a relatively high viscosity of $13000 \mathrm{mPa} \cdot \mathrm{s}$ (see Figure 13). ESO and EGS have different miscibility with DGEBA resin; however, EGS exhibited a much better viscosity reducing efficiency than ESO. A $30 \mathrm{wt} \%$ concentration of EGS reduced the DGEBA resin viscosity to value below $1000 \mathrm{mPa} \cdot \mathrm{s}$, which is indispensable for many applications. At

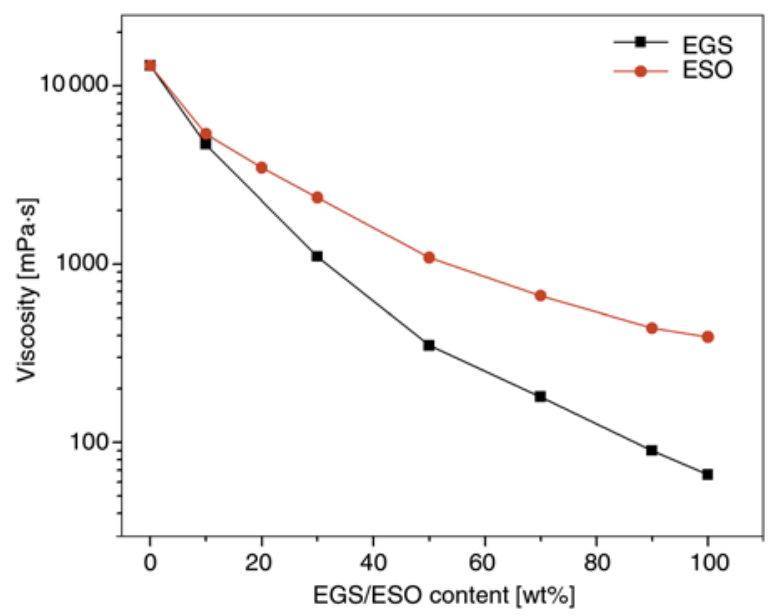

Figure 13. Viscosity of DGEBA blended with various EGS or ESO concentrations least $50 \mathrm{wt} \%$ of ESO was needed to reduce DGEBA resin to $1000 \mathrm{mPa} \cdot \mathrm{s}$ viscosity.

\section{Conclusions}

Bio-based epoxy resins, glycidyl ester of epoxidized fatty acids, were produced from soybean or linseed oils with a reduced saturated FFA fraction content. The products were characterized and showed high oxirane contents that were more reactive than ESO or ELO, which was shown to directly impact polymer homogeneity and glass transition temperature. Epoxy monomers from other vegetable oil sources such as canola, palm, corn, etc., could be fabricated in similar fashion and have similar properties and curing behaviors providing that saturated fatty ester chains are similarly removed.

The vegetable oil based epoxy resins displayed glass transitions that appear to be mostly a function of oxirane content but with additional influences of glycidyl versus internal oxirane reactivity, pendant chain content, and chemical structure and presence of saturated components. Generally, higher oxirane contents (epoxy functionality) lead to higher glass transition temperatures whereas reduced epoxy functionality, non-glycidyl FFA esters, and greater pendant chain contents lead to lower glass transition temperatures. In blends with DGEBA, monomers with only less reactive internal epoxies led to a more heterogeneous polymer structure compared to monomers possessing the more reactive glycidyl group and improved polymer homogeneity, in cure and structure. The inherent, long chain aliphatic structure of these thermoset monomers limits polymer glass transition temperatures compared to commercial, aromatic based epoxy monomers (DGEBA) but our data provide a clear trend and role of oxirane content.

The EGS blends with DGEBA were cured by MHHPA and their thermosetting polymer $T_{\mathrm{g}}$ 's measured in comparison to control ESO blends with DGEBA, which were polymerized in similar fashion. The EGS polymers displayed improved $T_{\mathrm{g}}$ 's and mechanical properties compared to their ESO counterparts and, in addition to an inherently low viscosity and efficient viscosity reduction, should therefore be more attractive as a reactive diluent. For instance, EGS derived from renewable sources could further enable defect-free fabrication of complex, shaped epoxy composites for structural com- 
posite applications. Our data show ESO produced less homogeneous polymers when blended with DGEBA epoxy that resulted in thermal cure, thermal property, and mechanically inferior materials compared to the more compatible EGS epoxy resin and blends. The compatibility and superior properties arise from the removal of saturated pendant chains, addition of the glycidyl structure, and larger internal oxirane content inherent of EGS.

\section{Acknowledgements}

Portions of this paper were presented at the 2011 Thermoset Resin Formulators Association annual meeting and at the 2012 American Oil Chemists' Society Annual Meeting \& Expo. Authors would like to thank Pranita Nayak and Dr. Rama Vuppalapati for assistance in resin synthesis and mechanical testing and acknowledge facilities and equipment support provided through the Missouri S\&T Materials Research Center.

Abbreviations
\begin{tabular}{|l|l|}
\hline DGEBA & diglycidyl ether of bisphenol A \\
\hline EAS & epoxidized allyl ester of soybean oil \\
\hline EMI & 2-ethyl-4-methylimidazole \\
\hline EMS & epoxidized methyl ester of soybean oil \\
\hline EPCH & epichlorohydrin \\
\hline EGL & $\begin{array}{l}\text { glycidyl esters of epoxidized fatty acids derived } \\
\text { from linseed oil }\end{array}$ \\
\hline EGL-P & EGL with partially epoxidized fatty acids \\
\hline EGL-S & EGL included saturated fatty acids \\
\hline EGS & $\begin{array}{l}\text { glycidyl esters of epoxidized fatty acids derived } \\
\text { from soybean oil }\end{array}$ \\
\hline EGS-P & EGS with partially epoxidized fatty acids \\
\hline EGS-S & EGS with saturated fatty acids \\
\hline ELO & epoxidized linseed oil \\
\hline ESO & epoxidized soybean oil \\
\hline EVO & epoxidized vegetable oils \\
\hline FA & fatty acid \\
\hline FFA & free fatty acid \\
\hline MCPBA & meta-chloroperoxybenzoic acid \\
\hline MHHPA & 4-methyl-1,2-cyclohexanedicarboxylic anhydride \\
\hline
\end{tabular}

\section{References}

[1] Raquez J-M., Deléglise M., Lacrampe M-F., Krawczak P.: Thermosetting (bio)materials derived from renewable resources: A critical review. Progress in Polymer Science, 35, 487-509 (2010). DOI: $10.1016 /$ j.progpolymsci.2010.01.001

[2] Gandini A.: Polymers from renewable resources: A challenge for the future of macromolecular materials. Macromolecules, 41, 9491-9504 (2008). DOI: $\underline{10.1021 / \mathrm{ma} 801735 \mathrm{u}}$
[3] Sharma V., Kundu P. P.: Addition polymers from natural oils - A review. Progress in Polymer Science, 31, 983-1008 (2006).

DOI: $10.1016 / \mathrm{j}$. progpolymsci.2006.09.003

[4] Pfister D. P., Xia Y., Larock R. C.: Recent advances in vegetable oil-based polyurethanes. ChemSusChem, 4 , 703-717 (2011).

DOI: $10.1002 /$ cssc. 201000378

[5] United Soybean Board: A survey of recent chemical price trends: The potential impact of rising petrochemical prices on soy use for industrial applications. Omni Tech International Ltd. (2010).

[6] Petrović Z. S.: Polyurethanes from vegetable oils. Polymer Reviews, 48, 109-155 (2008).

DOI: $10.1080 / 15583720701834224$

[7] Xia Y., Larock R. C.: Vegetable oil-based polymeric materials: Synthesis, properties, and applications. Green Chemistry, 12, 1893-1909 (2010).

DOI: $10.1039 / \mathrm{COGC00264J}$

[8] Lu J., Khot S., Wool R. P.: New sheet molding compound resins from soybean oil. I. Synthesis and characterization. Polymer, 46, 71-80 (2005).

DOI: $10.1016 /$ j.polymer.2004.10.060

[9] Campanella A., La Scala J. J., Wool R. P.: Fatty acidbased comonomers as styrene replacements in soybean and castor oil-based thermosetting polymers. Journal of Applied Polymer Science, 119, 1000-1010 (2011).

DOI: $10.1002 /$ app.32810

[10] Luo Q., Liu M., Xu Y., Ionescu M., Petrović Z. S.: Thermosetting allyl resins derived from soybean oil. Macromolecules, 44, 7149-7157 (2011).

DOI: $10.1021 / \mathrm{ma} 201366 \mathrm{e}$

[11] Lligadas G., Ronda J. C., Galià M., Cádiz V.: Plant oils as platform chemicals for polyurethane synthesis: Current state-of-the-art. Biomacromolecules, 11, 28252835 (2010). DOI: $10.1021 / \mathrm{bm} 100839 \mathrm{x}$

[12] Xu J., Liu Z., Erhan S., Carriere C. J.: Cross-linkers control the viscoelastic properties of soybean oil-based biomaterials. Journal of the American Oil Chemists' Society, 81, 813-816 (2004).

DOI: $10.1007 / \mathrm{s} 11746-004-0984-6$

[13] May C. A.: Epoxy resins chemistry and technology. Marcel Dekker, New York (1988).

[14] Raghavachar R., Sarnecki G., Baghdachi J., Massingill J.: Cationic, thermally cured coatings using epoxidized soybean oil. Journal of Coatings Technology, 72, 125-133 (2000). DOI: $10.1007 / \mathrm{bf02733784}$

[15] Chandrashekhara K., Sundararaman S., Flanigan V., Kapila S.: Affordable composites using renewable materials. Materials Science and Engineering: A, 412, 2-6 (2005).

DOI: $10.1016 /$ j.msea.2005.08.066 
[16] Tanrattanakul V., Saithai P.: Mechanical properties of bioplastics and bioplastic-organoclay nanocomposites prepared from epoxidized soybean oil with different epoxide contents. Journal of Applied Polymer Science, 114, 3057-3067 (2009).

DOI: 10.1002/app.30842

[17] Liu Z., Erhan S. Z., Akin D. E., Barton F. E.: 'Green' composites from renewable resources: Preparation of epoxidized soybean oil and flax fiber composites. Journal of Agricultural and Food Chemistry, 54, 2134 2137 (2006). DOI: $10.1021 / \mathrm{jf0} 526745$

[18] Stevens M. P.: Polymer chemistry: An introduction. Oxford University Press, New York (1999).

[19] Adamson M. J.: Thermal expansion and swelling of cured epoxy resin used in graphite/epoxy composite materials. Journal of Materials Science, 15, 17361745 (1980).

DOI: $10.1007 / \mathrm{bf00550593}$

[20] Gupta A. P., Ahmad S., Dev A.: Modification of novel bio-based resin-epoxidized soybean oil by conventional epoxy resin. Polymer Engineering and Science, 51, 1087-1091 (2011). DOI: $10.1002 /$ pen.21791

[21] Gelb L., Ault W., Palm W., Witnauer L., Port W.: Epoxy resins from fats. III. Preparation and properties of resins from blends of a commercial diglycidyl ether and epoxidized glycerides cured with phthalic anhydride. Journal of the American Oil Chemists' Society, 37, 81-84 (1960).

DOI: $10.1007 / \mathrm{bf02667729}$

[22] Czub P.: Characterization of an epoxy resin modified with natural oil-based reactive diluents. Macromolecular Symposia, 245-246, 533-538 (2006).

DOI: $10.1002 /$ masy.200651377

[23] Kar S., Banthia A. K.: Epoxy resin modified with epoxidized soybean rubber. Materials and Manufacturing Processes, 19, 459-474 (2004). DOI: 10.1081/AMP-120038655

[24] Miyagawa H., Misra M., Drzal L. T., Mohanty A. K.: Fracture toughness and impact strength of anhydridecured biobased epoxy. Polymer Engineering and Science, 45, 487-495 (2005).

DOI: $10.1002 /$ pen.20290

[25] Jin F-L., Park S-J.: Impact-strength improvement of epoxy resins reinforced with a biodegradable polymer. Materials Science and Engineering: A, 478, 402-405 (2008).

DOI: $10.1016 /$ j.msea.2007.05.053

[26] Tan S. G., Chow W. S.: Thermal properties of anhydride-cured bio-based epoxy blends. Journal of Thermal Analysis and Calorimetry, 101, 1051-1058 (2010). DOI: 10.1007/s10973-010-0751-7

[27] Thulasiraman V., Rakesh S., Sarojadevi M.: Synthesis and characterization of chlorinated soy oil based epoxy resin/glass fiber composites. Polymer Composites, 30, 49-58 (2008).

DOI: $10.1002 /$ pc. 20532
[28] Lligadas G., Ronda J. C., Galià M., Cádiz V.: Development of novel phosphorus-containing epoxy resins from renewable resources. Journal of Polymer Science Part A: Polymer Chemistry, 44, 6717-6727 (2006). DOI: $10.1002 /$ pola.21794

[29] Earls J. D., White J. E., López L. C., Lysenko Z., Dettloff M. L., Null M. J.: Amine-cured $\omega$-epoxy fatty acid triglycerides: Fundamental structure-property relationships. Polymer, 48, 712-719 (2007).

DOI: $10.1016 /$ j.polymer.2006.11.060

[30] Pan X., Sengupta P., Webster D. C.: High biobased content epoxy-anhydride thermosets from epoxidized sucrose esters of fatty acids. Biomacromolecules, 12, 2416-2428 (2011).

DOI: $10.1021 / \mathrm{bm} 200549 \mathrm{c}$

[31] Gerbase A. E., Petzhold C. L., Costa A. P. O.: Dynamic mechanical and thermal behavior of epoxy resins based on soybean oil. Journal of the American Oil Chemists' Society, 79, 797-802 (2002). DOI: $10.1007 / \mathrm{s} 11746-002-0561-\mathrm{Z}$

[32] La Scala J., Wool R. P.: Property analysis of triglyceride-based thermosets. Polymer, 46, 61-69 (2005). DOI: $10.1016 /$ j.polymer.2004.11.002

[33] Meier M. A. R., Metzger J. O., Schubert U. S.: Plant oil renewable resources as green alternatives in polymer science. Chemical Society Reviews, 36, 17881802 (2007). DOI: 10.1039/B703294C

[34] Nicolau A., Mariath R. M., Martini E. A., dos Santos Martini D., Samios D.: The polymerization products of epoxidized oleic acid and epoxidized methyl oleate with cis-1,2-cyclohexanedicarboxylic anhydride and triethylamine as the initiator: Chemical structures, thermal and electrical properties. Materials Science and Engineering: C, 30, 951-962 (2010).

DOI: $10.1016 / \mathrm{j} . \mathrm{msec} .2010 .04 .014$

[35] Zhu J., Chandrashekhara K., Flanigan V., Kapila S.: Curing and mechanical characterization of a soy-based epoxy resin system. Journal of Applied Polymer Science, 91, 3513-3518 (2004).

DOI: $10.1002 / a p p .13571$

[36] Reiznautt Q. B., Garcia I. T. S., Samios D.: Oligoesters and polyesters produced by the curing of sunflower oil epoxidized biodiesel with cis-cyclohexane dicarboxylic anhydride: Synthesis and characterization. Materials Science and Engineering: C, 29, 2302-2311 (2009).

DOI: $10.1016 /$ j.msec.2009.05.021

[37] dos Santos Martini D., Braga B. A., Samios D.: On the curing of linseed oil epoxidized methyl esters with different cyclic dicarboxylic anhydrides. Polymer, 50, 2919-2925 (2009).

DOI: $10.1016 /$ j.polymer.2009.03.058 
[38] Petrović Z. S., Guo A., Zhang W.: Structure and properties of polyurethanes based on halogenated and nonhalogenated soy-polyols. Journal of Polymer Science Part A: Polymer, 38, 4062-4069 (2000).

DOI: $10.1002 / 1099-0518(20001115) 38: 22<4062$ ::aidpola60>3.0.co;2-1

[39] Pan X., Sengupta P., Webster D. C.: Novel biobased epoxy compounds: Epoxidized sucrose esters of fatty acids. Green Chemistry, 13, 965-975 (2011).

DOI: $10.1039 / \mathrm{C} 0 \mathrm{GC} 00882 \mathrm{~F}$

[40] Zong Z., Soucek M. D., Liu Y., Hu J.: Cationic photopolymerization of epoxynorbornane linseed oils: The effect of diluents. Journal of Polymer Science Part A: Polymer Chemistry, 41, 3440-3456 (2003).

DOI: $10.1002 /$ pola. 10942

[41] Zou K., Soucek M. D.: UV-curable cycloaliphatic epoxide based on modified linseed oil: Synthesis, characterization and kinetics. Macromolecular Chemistry and Physics, 206, 967-975 (2005).

DOI: $10.1002 / \mathrm{macp} .200400390$

[42] Tan S. G., Chow W. S.: Thermal properties, curing characteristics and water absorption of soybean oilbased thermoset. Express Polymer Letters, 5, 480-492 (2011).

DOI: 10.3144/expresspolymlett.2011.47

[43] Petrović Z. S., Zhang W., Javni I.: Structure and properties of polyurethanes prepared from triglyceride polyols by ozonolysis. Biomacromolecules, 6, 713719 (2005).

DOI: $10.1021 / \mathrm{bm} 049451 \mathrm{~s}$

[44] Kiatsimkul P-P., Suppes G. J., Sutterlin W. R.: Production of new soy-based polyols by enzyme hydrolysis of bodied soybean oil. Industrial Crops and Products, 25, 202-209 (2007).

DOI: $10.1016 /$ j.indcrop.2006.10.001

[45] Vázquez L., Akoh C. C.: Concentration of stearidonic acid in free fatty acid and fatty acid ethyl ester forms from modified soybean oil by winterization. Journal of the American Oil Chemists' Society, 88, 1775-1785 (2011).

DOI: $10.1007 / \mathrm{s} 11746-011-1857-1$

[46] Sharma V., Kundu P. P.: Condensation polymers from natural oils. Progress in Polymer Science, 33, 11991215 (2008).

DOI: $10.1016 /$ j.progpolymsci.2008.07.004

[47] Chen J-S., Ober C. K., Poliks M. D., Zhang Y., Wiesner U., Cohen C.: Controlled degradation of epoxy networks: Analysis of crosslink density and glass transition temperature changes in thermally reworkable thermosets. Polymer, 45, 1939-1950 (2004). DOI: $10.1016 /$ j.polymer.2004.01.011

[48] Brown J. B.: Low-temperature crystallization of the fatty acids and glycerides. Chemical Reviews, 29, 333354 (1941).

DOI: $10.1021 / \mathrm{cr} 60093 \mathrm{a} 009$
[49] Brown J. B., Stoner G. G.: Studies on the chemistry of the fatty acids. I. The purification of linoleic acid by crystallization methods. Journal of the American Chemical Society, 59, 3-6 (1937). DOI: $10.1021 / \mathrm{ja} 01280 \mathrm{a} 002$

[50] Maerker G., Saggese E., Port W.: Glycidyl esters. II. Synthesis of esters of commercial and pure fatty acids. Journal of the American Oil Chemists' Society, 38, 194-197 (1961).

DOI: $10.1007 / \mathrm{bf02633229}$

[51] Kester E. B., Gaiser C. J., Lazar M. E.: Glycidyl esters of aliphatic acids. The Journal of Organic Chemistry, 8, 550-556 (1943).

DOI: $10.1021 / \mathrm{jo0} 1194 \mathrm{a} 010$

[52] Altuna F. I., Espósito L. H., Ruseckaite R. A., Stefani P. M.: Thermal and mechanical properties of anhydride-cured epoxy resins with different contents of biobased epoxidized soybean oil. Journal of Applied Polymer Science, 120, 789-798 (2011).

DOI: 10.1002/app.33097

[53] Boquillon N., Fringant C.: Polymer networks derived from curing of epoxidised linseed oil: Influence of different catalysts and anhydride hardeners. Polymer, 41, 8603-8613 (2000).

DOI: $10.1016 / \mathrm{s} 0032-3861(00) 00256-1$

[54] Ratna D.: Handbook of thermoset resins. Rapra, Shropshire (2009).

[55] Brandrup J., Immergut E. H., Grulke E. A., Abe A., Bloch D. R.: Polymer handbook. Wiley, New York (2005).

[56] Barton A. F. M.: Handbook of solubility parameters and other cohesion parameters. CRC Press, Boca Raton (1983).

[57] Van Krevelen D. W.: Properties of polymers. Elsevier, Amsterdam (1990).

[58] Jackson P. L., Huglin M. B., Cervenka A.: Use of inverse gas chromatography to quantify interactions in anhydride cured epoxy resins. Polymer International, 35, 135-143 (1994). DOI: $10.1002 /$ pi.1994.210350203

[59] Park S-J., Jin F-L., Lee J-R.: Thermal and mechanical properties of tetrafunctional epoxy resin toughened with epoxidized soybean oil. Materials Science and Engineering: A, 374, 109-114 (2004).

DOI: $10.1016 /$ j.msea.2004.01.002

[60] Frischinger I., Dirlikov S.: Two-phase interpenetrating epoxy thermosets that contain epoxidized triglyceride oils. Part I. Phase separation. in 'Interpenetrating polymer networks’ (Klempner D., Sperling L. H., Utracki L. A.) American Chemical Society, Washington, Vol 239, 517-538 (1994).

DOI: $10.1021 / \mathrm{ba}-1994-0239 . c h 025$

[61] Robeson L. M.: Polymer blends: A comprehensive review. Hanser, Cincinnati (2007).

[62] Ratna D., Banthia A. K.: Rubber toughened epoxy. Macromolecular Research, 12, 11-21 (2004). DOI: $10.1007 /$ bf03218989 
[63] Harsch M., Karger-Kocsis J., Herzog F., Fejős M.: Effect of cure regime on internal strain and stress development in a filled epoxy resin assessed by fiber Bragggrating optical strain and normal force measurements. Journal of Reinforced Plastics and Composites, 30, 1417-1427 (2011).

DOI: $10.1177 / 0731684411413625$

[64] Bell J. P.: Structure of a typical amine-cured epoxy resin. Journal of Polymer Science Part A-2: Polymer Physics, 8, 417-436 (1970). DOI: $10.1002 /$ pol.1970.160080308

[65] Bellenger V., Morel E., Verdu J.: Solubility parameters of amine-crosslinked aromatic epoxies. Journal of Applied Polymer Science, 37, 2563-2576 (1989).

DOI: 10.1002/app.1989.070370909

[66] Kwei T. K.: Swelling of highly crosslinked network structure. Journal of Polymer Science Part A: General Papers, 1, 2977-2988 (1963). DOI: $10.1002 /$ pol.1963.100010918

[67] Mahendran A. R., Wuzella G., Kandelbauer A., Aust N.: Thermal cure kinetics of epoxidized linseed oil with anhydride hardener. Journal of Thermal Analysis and Calorimetry, 107, 989-998 (2012).

DOI: 10.1007/s10973-011-1585-7

[68] Gao J., Li J., Benicewicz B. C., Zhao S., Hillborg H., Schadler L. S.: The mechanical properties of epoxy composites filled with rubbery copolymer grafted $\mathrm{SiO}_{2}$. Polymers, 4, 187-210 (2012).

DOI: $10.3390 /$ polym4010187

[69] Kim J. R., Sharma S.: The development and comparison of bio-thermoset plastics from epoxidized plant oils. Industrial Crops and Products, 36, 485-499 (2012). DOI: $10.1016 /$ j.indcrop.2011.10.036

[70] Miyagawa H., Mohanty A. K., Misra M., Drzal L. T.: Thermo-physical and impact properties of epoxy containing epoxidized linseed oil, 2. Macromolecular Materials and Engineering, 289, 636-641 (2004). DOI: $10.1002 /$ mame.200400003

[71] Lu P.: Curing chemistry of epoxidized soybean oil and its application for structural composite materials, $\mathrm{PhD}$ Thesis, University of Missouri-Rolla, Rolla (2001).

[72] Liu Z., Doll K. M., Holser R. A.: Boron trifluoride catalyzed ring-opening polymerization of epoxidized soybean oil in liquid carbon dioxide. Green Chemistry, 11, 1774-1789 (2009). DOI: $10.1039 / B 915742 \mathrm{P}$

[73] Liu Z., Erhan S. Z.: Ring-opening polymerization of epoxidized soybean oil. Journal of the American Oil Chemists' Society, 87, 437-444 (2009).

DOI: $10.1007 / \mathrm{s} 11746-009-1514-0$
[74] Czub P.: Application of modified natural oils as reactive diluents for epoxy resins. Macromolecular Symposia, 242, 60-64 (2006).

DOI: $10.1002 /$ masy.200651010

[75] Park S-J., Jin F-L., Lee J-R.: Synthesis and thermal properties of epoxidized vegetable oil. Macromolecular Rapid Communications, 25, 724-727 (2004).

DOI: 10.1002/marc.200300191

[76] Gelb L. L., Ault W. C., Palm W. E., Witnauer L. P., Port W. S.: Epoxy resins from fats. I. Epoxidized glycerides cured with phthalic anhydride. Journal of the American Oil Chemists' Society, 36, 283-286 (1959).

DOI: $10.1007 / \mathrm{bf02639997}$

[77] Tan S. G., Chow W. S.: Biobased epoxidized vegetable oils and its greener epoxy blends: A review. PolymerPlastics Technology and Engineering, 49, 1581-1590 (2010).

DOI: $10.1080 / 03602559.2010 .512338$

[78] Miyagawa H., Mohanty A. K., Misra M., Drzal L. T.: Thermo-physical and impact properties of epoxy containing epoxidized linseed oil, 1. Macromolecular Materials and Engineering, 289, 629-635 (2004). DOI: $10.1002 /$ mame. 200400004

[79] Tan S., Chow W. J.: Curing characteristics and thermal properties of epoxidized soybean oil based thermosetting resin. Journal of the American Oil Chemists' Society, 88, 915-923 (2011). DOI: $10.1007 / \mathrm{s} 11746-010-1748-\mathrm{x}$

[80] Miyagawa H., Misra M., Drzal L. T., Mohanty A. K.: Biobased epoxy/layered silicate nanocomposites: Thermophysical properties and fracture behavior evaluation. Journal of Polymers and the Environment, 13, 8796 (2005).

DOI: $10.1007 / \mathrm{s} 10924-005-2940-1$

[81] Nicolau A., Samios D., Piatnick C. M. S., Reiznautt Q. B., Martini D. D., Chagas A. L.: On the polymerisation of the epoxidised biodiesel: The importance of the epoxy rings position, the process and the products. European Polymer Journal, 48, 1266-1278 (2012). DOI: $10.1016 /$ j.eurpolymj.2012.04.013

[82] Varley R. J., Tian W.: Toughening of an epoxy anhydride resin system using an epoxidized hyperbranched polymer. Polymer International, 53, 69-77 (2004). DOI: $10.1002 /$ pi. 1324

[83] Mark H. F.: Encyclopedia of polymer science and technology. Wiley-Interscience, New York (2004). 